\title{
Ocorrência de condições inflamatórias pediátricas na COVID-19: uma revisão
}

\section{integrativa}

\author{
Occurrence of pediatric inflammatory conditions in COVID-19: an integrative review \\ Ocurrencia de condiciones inflamatorias pediátricas en COVID-19: una revisión integrativa
}

Recebido: 23/02/2021 | Revisado: 03/03/2021 | Aceito: 08/03/2021 | Publicado: 16/03/2021

\author{
Jefferson Fellyphe Rodrigues \\ ORCID: https://orcid.org/0000-0002-7711-1193 \\ Universidade Federal da Paraíba, Brasil \\ E-mail: jf_fellype@ @otmail.com \\ Eliza Juliana da Costa Eulálio \\ ORCID: https://orcid.org/0000-0002-7821-0732 \\ Universidade Federal da Paraíba, Brasil \\ E-mail: Elizafisioterapia@hotmail.com
}

\begin{abstract}
Resumo
Objetivo: integrar, compilar e discutir os dados clínico-epidemiológicos de pacientes pediátricos que foram expostos ao vírus SARS-CoV-2 e desenvolveram síndromes inflamatórias multissistêmicas. Metodologia: A pesquisa foi realizada no mês de setembro de 2020, a partir das bases eletrônicas de dados da Biblioteca Virtual em Saúde (BVS), Medical Literature Analysis and Retrieval System Online (MEDLINE), SCOPUS, Scientific Electronic Library Online (SciELO) e Google Scholar. Os descritores foram organizados na seguinte proposta: ("COVID-19" OR "SARS-CoV-2" OR "Coronavirus" AND "Kawasaki Disease" AND "Children" OR "Adolescent" OR "Pediatric") OR ("COVID-19” OR "SARS-CoV-2" OR "Coronavirus" AND "Multisystem Inflammatory Syndrome in Children" OR "Pediatric Multisystem Inflammatory Syndrome” AND “Children” OR “Adolescent” OR "Pediatric”)). As buscas foram delimitadas pelos critérios de inclusão: idioma (inglês, português e espanhol), indexação nos bancos de dados e texto na integra. Os critérios de exclusão foram: estudos inadequados, amostras duplicadas e incompatíveis com o objetivo desta revisão. Resultados: Foram identificados 1.324 artigos dos quais apenas 38 foram incluídos na revisão. A maioria dos pacientes era sexo masculino (59\%), afrodescendentes (35\%) com idade média de 8,8 anos. A Síndrome inflamatória multissistêmica pediátrica foi diagnosticada em $67 \%$ dos pacientes que apresentaram principalmente febre (94\%), sintomas gastrointestinais (65\%) e possíveis complicações cardíacas (32\%), hipotensão (27\%) e choque (17\%). Conclusão: As informações apontam para uma síndrome pós-viral que surge entre duas e quatro semanas após a contaminação pelo Sars-CoV-2, os impactos causados ainda são desconhecidos, portanto, as equipes dos serviços de saúde devem estar atentas para lidarem com esse novo aspecto da COVID-19.
\end{abstract}

Palavras-chave: COVID-19; SARS-CoV-2; Doença de Kawasaki; MIS-C; Crianças.

\begin{abstract}
Objective: to integrate, compile and discuss the clinical-epidemiological data of pediatric patients who were exposed to the SARS-CoV-2 virus and developed multisystemic inflammatory syndromes. Methodology: The research was carried out in September 2020, from the electronic databases of the Biblioteca Virtual em Saúde (BVS), Medical Literature Analysis and Retrieval System Online (MEDLINE), SCOPUS, Scientific Electronic Library Online (SciELO) and Google Scholar. The descriptors were organized in the following proposal: ((“" COVID-19 "OR" SARS-CoV-2 "OR" Coronavirus "AND“ Kawasaki Disease "AND“ Children "OR" Adolescent "OR" Pediatric ") OR (“ COVID- 19 "OR" SARS-CoV-2 "OR" Coronavirus "AND“ Multisystem Inflammatory Syndrome in Children "OR“ Pediatric Multisystem Inflammatory Syndrome "AND“ Children "OR“ Adolescent "OR“ Pediatric ")). The searches were delimited by the inclusion criteria: language (English, Portuguese and Spanish), indexing in the databases and full text. The exclusion criteria were: inadequate studies, duplicate samples and incompatible with the purpose of this review. Results: 1,324 articles were identified, of which only 38 were included in the review. The majority of patients were male (59\%), African-American $(35 \%)$ with an average age of 8.8 years. Pediatric multisystem inflammatory syndrome was diagnosed in $67 \%$ of patients who presented mainly fever $(94 \%)$, gastrointestinal symptoms (65\%) and possible cardiac complications (32\%), hypotension (27\%) and shock (17\%). Conclusion: The information points to a post-viral syndrome that appears between two and four weeks after contamination by Sars-CoV-2, the impacts caused are still unknown, therefore, health service teams must be attentive to deal with this new aspect of COVID-19.
\end{abstract}

Keywords: COVID-19; SARS-CoV-2; Kawasaki disease; MIS-C; Children. 


\begin{abstract}
Resumen
Objetivo: integrar, recopilar y discutir los datos clínico-epidemiológicos de pacientes pediátricos que estuvieron expuestos al virus SARS-CoV-2 y desarrollaron síndromes inflamatorios multisistémicos. Metodología: La investigación se realizó en septiembre de 2020, a partir de las bases de datos electrónicas de la Biblioteca Virtual em Saúde (BVS), Medical Literature Analysis and Retrieval System Online (MEDLINE), SCOPUS, Scientific Electronic Library Online (SciELO) y Google Scholar. Los descriptores se organizaron en la siguiente propuesta: ("“" COVID19 "O" SARS-CoV-2 "O" Coronavirus "Y" Enfermedad de Kawasaki "Y" Niños "O" Adolescente "O" Pediátrico ") O (" COVID-19 "O" SARS-CoV-2 "O" Coronavirus "Y" Síndrome inflamatorio multisistémico en niños "O" Síndrome inflamatorio multisistémico pediátrico "Y" Niños "O" Adolescente "O" Pediátrico ")). Las búsquedas se delimitaron por los criterios de inclusión: idioma (inglés, portugués y español), indexación en las bases de datos y texto completo. Los criterios de exclusión fueron: estudios inadecuados, muestras duplicadas e incompatibles con el propósito de esta revisión. Resultados: Se identificaron 1.324 artículos, de los cuales solo 38 fueron incluidos en la revisión. La mayoría de los pacientes eran hombres (59\%), afroamericanos (35\%) con una edad promedio de 8.8 años. Se diagnosticó Síndrome inflamatorio multisistémico pediátrico en el $67 \%$ de los pacientes que presentaron principalmente fiebre (94\%), síntomas gastrointestinales $(65 \%)$ y posibles complicaciones cardíacas (32\%), hipotensión (27\%) y shock (17\%). Conclusión: La información apunta a un síndrome post-viral que aparece entre dos y cuatro semanas después de la contaminación por Sars-CoV-2, aún se desconocen los impactos ocasionados, por lo que los equipos de servicios de salud deben estar atentos para enfrentar este nuevo aspecto del COVID -19.
\end{abstract}

Palabras clave: COVID-19; SARS-CoV-2; Enfermedad de Kawasaki; MIS-C; Niños.

\title{
1. Introdução
}

No final de dezembro de 2019 uma epidemia de infecção por um novo corona vírus eclodiu na cidade de Wuhan na China. A infecção espalhou-se por todo o país e ganhou projeção internacional atingindo mais de 188 países. A pneumonia de causa desconhecida com manifestações clínicas semelhantes a síndrome respiratória aguda grave foi denominada pela Organização Mundial de Saúde como COVID-19 e o agente causador como SARS-CoV-2 (Wang et al., 2020).

Até o dia 31 de dezembro de 2020, a COVID-19 atingiu 82.820.052 pessoas globalmente, vitimando $1.807 .331 \mathrm{em}$ todo o planeta. No Brasil, estima-se que o número de casos confirmados esteja por volta de 7.619.200 com um quantitativo de 193.875 mortes (Hopkins, 2020). Os sintomas da infecção por COVID-19 aparecem após um período de incubação de aproximadamente 5 dias, o início dos sintomas até a morte tem variado entre 6 e 41 dias com média de 14 dias conforme idade e condições de resposta do sistema imunológico do paciente (Li et al., 2020; G. Wang et al., 2020). Pacientes pediátricos representam entre 1 e 5\% dos casos diagnosticados com período de incubação entre 2 e 10 dias (Ludvigsson, 2020).

No público adulto, em geral, 14\% dos casos de COVID-19 são graves e 5\% necessitam de cuidados intensivos (Wu \& McGoogan, 2020), em contrapartida, o público pediátrico apresentou sintomas mais brandos da doença (Jiehao et al., 2020; Wang et al., 2020). Os aspectos envolvidos nos quadros mais leves das crianças ainda são desconhecidos, é possível que o público pediátrico não apresente uma desregulação do seu sistema imune ao serem expostos ao vírus, mantendo uma contagem habitual de linfócitos, de proteína-C-reativa e funções hepáticas normais. As crianças também podem ter uma expressão menor do receptor ECA-2 dificultando a entrada do vírus no citoplasma celular, além de obterem uma produção significativa de anticorpos contra outros vírus desempenhando ações imunológicas contra o SARS-CoV-2 (Joseph, 2020; Ong et al., 2020).

Um estudo realizado no Hospital Infantil de Wuhan com 171 crianças com COVID-19 demonstrou que os sintomas mais comuns foram a tosse (48\%), eritema faríngeo (46\%) e febre $(41,5 \%)$, outros sintomas incluíram diarreia, fadiga, rinorreia e congestão nasal. Apenas $29 \%$ apresentaram taquipneia e 2\% hipoxemia (saturação < $92 \%$ ) durante a hospitalização (Lu et al., 2020). Mesmo com quadros leves da doença, alguns estudos têm demonstrado crianças com inflamação multissistêmica e manifestações clínicas semelhantes a doença de Kawasaki pós infecção por SARS-CoV-2. As crianças apresentavam febre alta e persistente, erupções cutâneas, edema nas extremidades, conjuntivite não purulenta, dor abdominal, vômitos e diarreia. Em sua grande maioria, o quadro evoluiu para choque cardiogênico com elevação das enzimas miocárdicas e inflamação de serosas com derrame pleural, pericárdico e ascite. Além da necessidade de suporte ventilatório mesmo sem manifestações relevantes na condição pulmonar (Riphagen et al., 2020). 
A doença de Kawasaki (KD) é caracterizada como um distúrbio inflamatório multissistêmico que acomete pequenos e médios vasos, é uma doença que tem maior predominância em crianças com idade entre seis meses e cinco anos (Agarwal \& Agrawal, 2017). Sua incidência é maior nos países asiáticos (300/100.000) em comparação com países Europeus (5/100.000) ou com países na América do Norte (19/1.000.000) (Kim, 2019). A causa da doença é desconhecida e o diagnóstico é clínico mediante observação de sinais e sintomas predeterminados como febre prolongada igual ou superior a 5 dias, conjuntivite bilateral não exudativa, linfadenopatia cervical, exantema polimórfico (maculopapular, eritema difuso ou eritema multiforme), alterações labiais ou da mucosa orofaríngea (queilite, língua em framboesa ou eritema orofaríngeo) e alterações das extremidades (eritema e edema palmo-plantares) (de Graeff et al., 2019; Newburger et al., 2004).

Toda via, a associação dessa nova manifestação da COVID-19 em crianças e adolescente com a doença de Kawasaki logo se mostrou insuficiente, as evidências apontam para uma nova síndrome associada à COVID-19 com características inflamatórias graves. Com base nos relatos e estudos publicados no transcorrer da pandemia, a nova síndrome foi denominada como síndrome inflamatória multissistêmica pediátrica (do inglês: multisystem inflammatory syndrome in children — MIS-C) associada à COVID-19. Além de sintomas abdominais incomuns, maiores comprometimentos cardíacos e marcadores inflamatórios excessivos, a MIS-C, a princípio, acomete crianças acima dos 5 anos de idade e com predomínio da etnia afrodescendente (Farias et al., 2020; Fornell, 2020; Verdoni et al., 2020).

O diagnóstico da MIS-C deve ser considerado em crianças e adolescentes de 0 a 19 anos com características da doença de Kawasaki típica ou atípica ou síndrome de choque, que apresentem febre superior a três dias e dois dos seguintes critérios: erupção cutânea ou conjuntivite não purulenta bilateral ou sinais de inflamação mucocutânea (oral, mãos ou pés); hipotensão ou choque; características de disfunção miocárdica, pericardite, valvulite ou anormalidades coronárias (incluindo achados ecocardiográficos) ou elevação de troponina, NT-proBNP; evidência de coagulopatia (por TP, TTPA, dímeros D elevados); problemas gastrointestinais agudos (diarreia, vômito ou dor abdominal); e marcadores elevados de inflamação: VHS, PCR ou procalcitonina. Além de nenhuma outra causa microbiana óbvia de inflamação: Sepse bacteriana, síndromes de choque estafilocócico ou estreptocócico. E evidência ou provável contato com pacientes com COVID-19: RT-PCR, teste antigênico ou sorológico positivo (WHO, 2020).

No Brasil, até o dia 10 de outubro de 2020, foram confirmados 486 casos da MIS-C com registro de 34 óbitos (letalidade de 7\%). A predominância é do sexo masculino (54\%) em crianças de 0 a 4 anos (40\%) e 5 a 9 anos (32\%). A maior concentração de casos notificados encontra-se nos estados de São Paulo, Ceará e Pará e Rio de Janeiro. Na Paraíba, foram registrados 10 casos com total de 2 óbitos (Brasil, 2020). No atual cenário pandêmico, a qualificação da informação é fundamental para o entendimento do curso evolutivo da doença, suas manifestações e repercussões na população. O público pediátrico, que a princípio apresentou manifestações mais brandas da COVID-19, parece seguir uma vertente com prováveis complicações graves a saúde.

A síndrome inflamatória multissistêmica pediátrica acometeu um pequeno grupo de crianças e adolescentes diante dos expressivos números de uma pandemia global. No entanto, o aprofundamento do conhecimento clinico-epidemiológico sobre essa nova síndrome pode impactar em decisões estratégicas na condução da pandemia. Situações como volta as aulas, maior rigidez nos cuidados preventivos, a busca de protocolos que permitam identificar precocemente o surgimento da síndrome e um tratamento eficaz devem incluir esse novo cenário em sua ótica. Diante do exposto, a presente revisão tem como objetivo integrar, compilar e discutir os dados clínico-epidemiológicos de pacientes pediátricos que foram expostos ao vírus SARSCoV-2 e desenvolveram síndromes inflamatórias multissistêmicas (KD e MIS-C).

\section{Metodologia}

Trata-se de uma revisão integrativa de literatura do tipo descritiva com abordagem quantitativa. O método 
quantitativo utiliza-se da coleta de dados numéricos por meio da geração de conjuntos de dados que podem ser analisados estatisticamente resultando em processos de previsão de acontecimentos (Pereira et al., 2018). A pesquisa foi realizada no mês de setembro de 2020, a partir das bases eletrônicas de dados da Biblioteca Virtual em Saúde (BVS), Mediacal Literature Analysis and Retrieval System Online (MEDLINE), SCOPUS, Scientific Electronic Library Online (SciELO) e o Google Scholar.

Os descritores foram selecionados conforme consulta no dicionário de Descritores em Ciência da Saúde (DeCS) e organizados com operadores booleanos na seguinte proposta: (("COVID-19" OR "SARS-CoV-2" OR "Coronavirus" AND "Kawasaki Disease" AND "Children" OR "Adolescent" OR "Pediatric") OR ("COVID-19” OR "SARS-CoV-2" OR "Coronavirus" AND "Multisystem Inflammatory Syndrome in Children" OR "Pediatric Multisystem Inflammatory Syndrome" AND "Children" OR "Adolescent" OR "Pediatric")). Os descritores e operadores foram adequados conforme características específicas das bases de dados.

As buscas foram delimitadas pelos critérios de inclusão: idioma (inglês, português e espanhol), indexação nos referidos bancos de dados e texto na integra. Os critérios de exclusão eliminaram estudos inadequados a revisão (dissertações, teses, monografias, reportagem, notícias, cartas ao editor, revisões), amostras duplicadas e incompatíveis com o objetivo (teste negativo para SARS-CoV-2, paciente adulto). A Figura 1 apresenta o fluxograma das buscas nas bases de dados e o resultante dos artigos selecionados na amostra final, totalizando 38 artigos selecionados.

Para registro, organização e análise das informações foi elaborado um instrumento de coleta de dados no programa Microsoft Excel estruturado em duas categorias: 1) identificação dos artigos (autoria, título do artigo, local de realização, revista da publicação, desenho do estudo), e 2) Síntese dos resultados (amostra, dados sociodemográficos, dados da hospitalização, diagnóstico diferencial e desfecho). A análise das informações foi realizada através de estatística descritiva no próprio Microsoft Excel. Todas as informações extraídas dos estudos utilizados são de domínio público, por tanto, foi respeitado a integridade das informações relatadas pelos autores cumprindo-se assim o dever ético com os mesmos.

Figura 1 - Fluxograma do processo de seleção dos artigos e amostragem final.
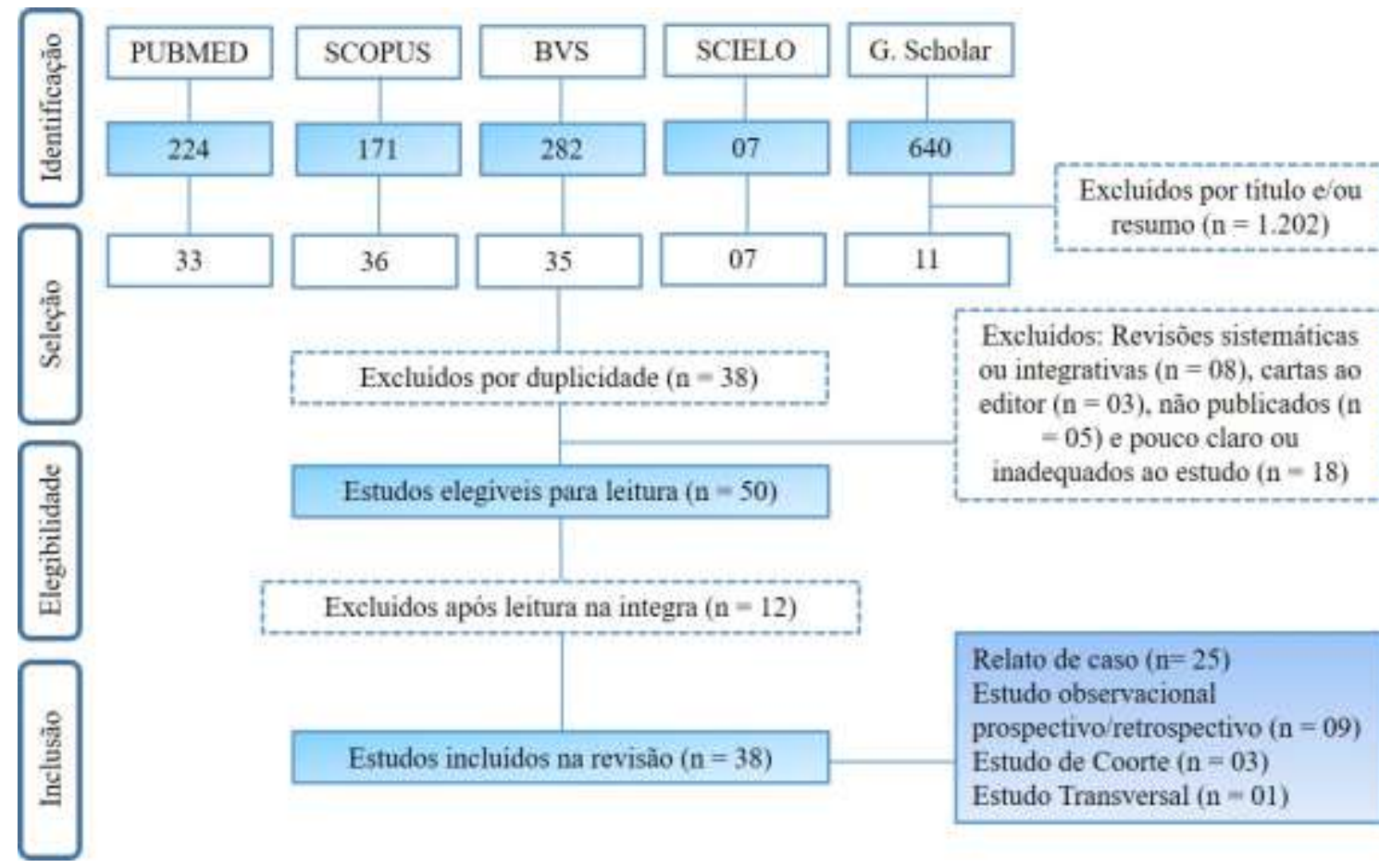

Relato de caso $(n=25)$

Estudo observacional

prospectivo/retrospectivo $(\mathrm{n}=09)$

Estudo de Coorte $(n=03)$

Estudo Transversal $(\mathrm{n}=01$ )

Fonte: Autores. 


\section{Resultados}

Foram identificados inicialmente 1.324 artigos dos quais 122 foram selecionados após exclusão por leitura do título ou resumo. Destes, apenas 50 foram elegíveis para leitura na integra, totalizando uma amostra final de 38 artigos incluídos na revisão. A Tabela 1 apresenta os dados extraídos dos artigos selecionados abordando informações sobre autoria, título do artigo, local de realização, revista da publicação e desenho do estudo respectivo. Dos 38 artigos selecionados obtivemos um total de vinte e cinco relatos de casos, nove estudos observacionais, três estudos de coorte e um estudo transversal.

Tabela 1 - Identificação dos artigos selecionados.

\begin{tabular}{|c|c|c|c|c|}
\hline Autores & Título & Local & Revista & $\begin{array}{l}\text { Tipo de } \\
\text { estudo }\end{array}$ \\
\hline $\begin{array}{l}\text { (Alnashri et } \\
\text { al., 2020) }\end{array}$ & $\begin{array}{c}\text { A challenging case of multisystem inflammatory syndrome } \\
\text { in children related to coronavirus Disease-19 hospitalized } \\
\text { under adult medical service }\end{array}$ & $\begin{array}{l}\text { Arábia } \\
\text { Saudita }\end{array}$ & IDCases & Relato de caso \\
\hline $\begin{array}{l}\text { (Bahrami et } \\
\text { al., 2020) }\end{array}$ & $\begin{array}{c}\text { Hyperinflammatory shock related to COVID-19 in a patient } \\
\text { presenting with multisystem inflammatory syndrome in } \\
\text { children: First case from Iran }\end{array}$ & Iran & $\begin{array}{l}\text { Journal of Paediatrics } \\
\text { and Child Health }\end{array}$ & Relato de caso \\
\hline $\begin{array}{l}\text { (Belhadjer et } \\
\text { al., 2020) }\end{array}$ & $\begin{array}{l}\text { Acute Heart Failure in Multisystem Inflammatory } \\
\text { Syndrome in Children in the Context of Global SARS-CoV- } \\
2 \text { Pandemic }\end{array}$ & França & Circulation & $\begin{array}{l}\text { Observacional } \\
\text { retrospectivo }\end{array}$ \\
\hline $\begin{array}{l}\text { (Burger et al., } \\
\text { 2020) }\end{array}$ & $\begin{array}{l}\text { Case Report: Pediatric Patient with COVID-19 and } \\
\text { Multisystem Inflammatory Syndrome in Children }\end{array}$ & $\begin{array}{l}\text { Estados } \\
\text { Unidos }\end{array}$ & $\begin{array}{l}\text { Clinical Practice and } \\
\text { Cases in Emergency } \\
\text { Medicine }\end{array}$ & Relato de caso \\
\hline $\begin{array}{l}\text { (Capone et al., } \\
\text { 2020) }\end{array}$ & $\begin{array}{c}\text { Characteristics, Cardiac Involvement, and Outcomes of } \\
\text { Multisystem Inflammatory Syndrome of Childhood } \\
\text { Associated with severe acute respiratory syndrome } \\
\text { coronavirus } 2 \text { Infection }\end{array}$ & $\begin{array}{l}\text { Estados } \\
\text { Unidos }\end{array}$ & $\begin{array}{l}\text { The Journal of } \\
\text { Pediatrics }\end{array}$ & $\begin{array}{l}\text { Observacional } \\
\text { retrospectivo }\end{array}$ \\
\hline $\begin{array}{l}\text { (Carter et al., } \\
\text { 2020) }\end{array}$ & $\begin{array}{c}\text { Peripheral immunophenotypes in children with multisystem } \\
\text { inflammatory syndrome associated with SARS-CoV-2 } \\
\text { infection }\end{array}$ & $\begin{array}{l}\text { Reino } \\
\text { Unido }\end{array}$ & Nature medicine & $\begin{array}{l}\text { Estudo de } \\
\text { coorte }\end{array}$ \\
\hline $\begin{array}{l}\text { (Cazzaniga et } \\
\text { al., 2020) }\end{array}$ & $\begin{array}{l}\text { SARS-COV-2 Infection and Kawasaki Disease: Case } \\
\text { Report of a Hitherto Unrecognized Association }\end{array}$ & Itália & Frontiers in Pediatrics & Relato de caso \\
\hline $\begin{array}{l}\text { (Chiotos et al., } \\
\text { 2020) }\end{array}$ & $\begin{array}{l}\text { Multisystem Inflammatory Syndrome in Children During } \\
\text { the Coronavirus } 2019 \text { Pandemic: A Case Series }\end{array}$ & $\begin{array}{l}\text { Estados } \\
\text { Unidos }\end{array}$ & $\begin{array}{l}\text { Journal of the Pediatric } \\
\text { Infectious Diseases } \\
\text { Society }\end{array}$ & Série de casos \\
\hline $\begin{array}{c}\text { (Chiu et al., } \\
2020)\end{array}$ & $\begin{array}{c}\text { Kawasaki Disease Features and Myocarditis in a Patient } \\
\text { with COVID-19 }\end{array}$ & $\begin{array}{l}\text { Estados } \\
\text { Unidos } \\
\end{array}$ & Pediatric Cardiology & Relato de caso \\
\hline $\begin{array}{l}\text { (De Paulis et } \\
\text { al., 2020) }\end{array}$ & $\begin{array}{c}\text { Multisystem inflammatory syndrome Associated with } \\
\text { covid-19 with neurologic Manifestations in a child: a brief } \\
\text { report }\end{array}$ & Brasil & $\begin{array}{l}\text { The Pediatric Infectious } \\
\text { Disease Journal }\end{array}$ & Relato de caso \\
\hline $\begin{array}{l}\text { (Farias et al., } \\
\text { 2020) }\end{array}$ & $\begin{array}{l}\text { Multisystem inflammatory syndrome in a child associated } \\
\text { with coronavírus Disease } 19 \text { in the brazilian amazon: Fatal } \\
\text { outcome in an infant }\end{array}$ & Brasil & $\begin{array}{l}\text { Revista Paulista } \\
\text { Pediatria }\end{array}$ & Relato de caso \\
\hline $\begin{array}{l}\text { (de Farias et } \\
\text { al., } 2020\end{array}$ & $\begin{array}{l}\text { Multisystem inflammatory syndrome associated with } \\
\text { coronavirus disease in Children }\end{array}$ & Brasil & $\begin{array}{l}\text { The Pediatric Infectious } \\
\text { Disease Journal }\end{array}$ & $\begin{array}{c}\text { Observacional } \\
\text { prospectivo }\end{array}$ \\
\hline $\begin{array}{l}\text { (Ng et al., } \\
2020)\end{array}$ & $\begin{array}{l}\text { COVID-19 multisystem inflammatory syndrome in three } \\
\text { teenagers with confirmed SARS-CoV-2 infection }\end{array}$ & $\begin{array}{l}\text { Reino } \\
\text { Unido }\end{array}$ & $\begin{array}{l}\text { Journal of medical } \\
\text { virology Wiley }\end{array}$ & Série de casos \\
\hline $\begin{array}{l}\text { (Greene et al., } \\
2020)\end{array}$ & $\begin{array}{l}\text { Toxic shock-like syndrome and COVID-19: A case report } \\
\text { of multisystem inflammatory syndrome in children (MIS-C) }\end{array}$ & $\begin{array}{l}\text { Estados } \\
\text { Unidos } \\
\end{array}$ & $\begin{array}{l}\text { American Journal of } \\
\text { Emergency Medicine }\end{array}$ & Relato de caso \\
\hline $\begin{array}{l}\text { (Grimaud et } \\
\text { al., 2020) }\end{array}$ & $\begin{array}{c}\text { Acute myocarditis and multisystem infammatory emerging } \\
\text { disease following SARS-CoV-2 infection in critically ill } \\
\text { children }\end{array}$ & França & Ann. Intensive Care & $\begin{array}{l}\text { Observacional } \\
\text { retrospectivo }\end{array}$ \\
\hline $\begin{array}{l}\text { (Heidemann et } \\
\text { al., 2020) }\end{array}$ & $\begin{array}{l}\text { Three Cases of Pediatric Multisystem Inflammatory } \\
\text { Syndrome Associated with COVID-19 Due to SARS-CoV- } \\
2\end{array}$ & $\begin{array}{l}\text { Estados } \\
\text { Unidos }\end{array}$ & $\begin{array}{l}\text { American Journal of } \\
\text { Case Reports }\end{array}$ & Série de casos \\
\hline $\begin{array}{l}\text { (Jones et al., } \\
2020)\end{array}$ & $\begin{array}{l}\text { COVID-19 and Kawasaki Disease: Novel Virus and Novel } \\
\text { Case }\end{array}$ & $\begin{array}{l}\text { Estados } \\
\text { Unidos }\end{array}$ & Hospital Pediatrics & Relato de caso \\
\hline $\begin{array}{l}\text { (Kaushik et al., } \\
\text { 2020) }\end{array}$ & $\begin{array}{c}\text { Multisystem Inflammatory Syndrome in Children } \\
\text { Associated with Severe Acute Respiratory Syndrome } \\
\text { Coronavirus } 2 \text { Infection (MIS-C): A Multi-institutional } \\
\text { Study from New York City } \\
\end{array}$ & $\begin{array}{l}\text { Estados } \\
\text { Unidos }\end{array}$ & $\begin{array}{l}\text { The Journal Of } \\
\text { Pediatrics }\end{array}$ & $\begin{array}{l}\text { Observacional } \\
\text { retrospectivo }\end{array}$ \\
\hline $\begin{array}{c}\text { (Kest et al., } \\
2020)\end{array}$ & $\begin{array}{l}\text { Multisystem Inflammatory Syndrome in Children (MIS-C) } \\
\text { Associated with } 2019 \text { Novel Coronavirus (SARS-CoV-2) }\end{array}$ & $\begin{array}{l}\text { Estados } \\
\text { Unidos } \\
\end{array}$ & $\begin{array}{l}\text { Case Reports in } \\
\text { Pediatrics }\end{array}$ & Série de casos \\
\hline
\end{tabular}




\begin{tabular}{|c|c|c|c|c|}
\hline & Infection & & & \\
\hline $\begin{array}{l}\text { (Klocperk et } \\
\text { al., 2020) }\end{array}$ & $\begin{array}{l}\text { Case Report: Systemic Inflammatory Response and Fast } \\
\text { Recovery in a Pediatric Patient With COVID-19 }\end{array}$ & $\begin{array}{l}\text { República } \\
\text { Tcheca }\end{array}$ & $\begin{array}{l}\text { Frontiers in } \\
\text { Immunology }\end{array}$ & Relato de caso \\
\hline $\begin{array}{l}\text { (Licciardi et } \\
\text { al., 2020) }\end{array}$ & $\begin{array}{c}\text { SARS-CoV-2-Induced Kawasaki-Like Hyperinflammatory } \\
\text { Syndrome: A Novel COVID Phenotype in Children }\end{array}$ & Itália & Pediatrics & $\begin{array}{l}\text { Relato de } \\
\text { casos }\end{array}$ \\
\hline $\begin{array}{l}\text { (Mahajan et } \\
\text { al., 2020) }\end{array}$ & $\begin{array}{c}\text { Case of multisystem inflammatory syndrome in children } \\
\text { presenting as fever and abdominal pain }\end{array}$ & $\begin{array}{l}\text { Estados } \\
\text { Unidos }\end{array}$ & $\mathrm{BMJ}$ & Relato de caso \\
\hline $\begin{array}{l}\text { (Mamishi et } \\
\text { al., 2020) }\end{array}$ & $\begin{array}{l}\text { Multisystem inflammatory syndrome associated with } \\
\text { SARS-CoV-2 infection in } 45 \text { children: a first report from } \\
\text { Iran }\end{array}$ & Iran & $\begin{array}{l}\text { Epidemiology and } \\
\text { Infection }\end{array}$ & $\begin{array}{l}\text { Observacional } \\
\text { retrospectivo }\end{array}$ \\
\hline $\begin{array}{l}\text { (Masih et al., } \\
\text { 2020) }\end{array}$ & $\begin{array}{l}\text { Paediatric case of prolonged COVID-19 manifesting as } \\
\text { PMIS-TS and atypical Kawasaki }\end{array}$ & $\begin{array}{l}\text { Reino } \\
\text { Unido }\end{array}$ & BMJ & Relato de caso \\
\hline $\begin{array}{l}\text { (Moazzam et } \\
\text { al., 2020) }\end{array}$ & $\begin{array}{c}\text { COVID-19 Multisystem Inflammatory Syndrome in } \\
\text { Children (MIS-C) simulating as acute appendicitis: A case } \\
\text { report }\end{array}$ & Paquistão & $\begin{array}{l}\text { Journal of Pediatric and } \\
\text { Adolescent Surgery }\end{array}$ & Relato de caso \\
\hline $\begin{array}{l}\text { (Moraleda et } \\
\text { al., 2020) }\end{array}$ & $\begin{array}{c}\text { Multi-inflammatory Syndrome in Children Related to } \\
\text { Severe Acute Respiratory Syndrome Coronavirus } 2 \text { (SARS- } \\
\text { CoV-2) in Spain }\end{array}$ & Espanha & $\begin{array}{l}\text { Clinical Infectious } \\
\text { Diseases }\end{array}$ & $\begin{array}{l}\text { Epidemiológic } \\
\text { o }\end{array}$ \\
\hline $\begin{array}{l}\text { (Nguyen et al., } \\
2020)\end{array}$ & $\begin{array}{c}\text { Pediatric Case of Severe COVID-19 With Shock and } \\
\text { Multisystem Inflammation }\end{array}$ & $\begin{array}{l}\text { Estados } \\
\text { Unidos }\end{array}$ & Cureus & Relato de caso \\
\hline $\begin{array}{l}\text { (Pouletty et al., } \\
\text { 2020) }\end{array}$ & $\begin{array}{l}\text { Paediatric multisystem inflammatory syndrome temporally } \\
\text { associated with SARS-CoV-2 mimicking Kawasaki disease } \\
\text { (Kawa-COVID-19): a multicentre cohort }\end{array}$ & França & Clinical science & $\begin{array}{l}\text { Estudo de } \\
\text { coorte }\end{array}$ \\
\hline $\begin{array}{l}\text { (Pereira et al., } \\
\text { 2020) }\end{array}$ & $\begin{array}{l}\text { Severe clinical spectrum with high mortality in pediatric } \\
\text { patients with COVID-19 and multisystem inflammatory } \\
\text { syndrome }\end{array}$ & Brasil & Clinics & $\begin{array}{l}\text { Estudo } \\
\text { transversal }\end{array}$ \\
\hline $\begin{array}{l}\text { (Raut et al., } \\
2020)\end{array}$ & $\begin{array}{l}\text { Incomplete Kawasaki Disease as Presentation of COVID-19 } \\
\text { Infection in an Infant: A Case Report }\end{array}$ & Índia & $\begin{array}{l}\text { Journal of Tropical } \\
\text { Pediatrics }\end{array}$ & Relato de caso \\
\hline $\begin{array}{l}\text { (Regev et al., } \\
\text { 2020) }\end{array}$ & $\begin{array}{c}\text { Pediatric inflammatory multisystem Syndrome with central } \\
\text { nervous system Involvement and hypocomplementemia } \\
\text { Following sars-cov-2 infection }\end{array}$ & Israel & $\begin{array}{l}\text { The Pediatric Infectious } \\
\text { Disease Journal }\end{array}$ & Relato de caso \\
\hline $\begin{array}{l}\text { (Sampaio et } \\
\text { al., 2020) }\end{array}$ & $\begin{array}{l}\text { Relato de caso: síndrome inflamatória multissistêmica } \\
\text { associada à infecção pelo Sars-cov-2 em pediatria }\end{array}$ & Brasil & Residência Pediátrica & Relato de caso \\
\hline $\begin{array}{c}\text { (Spencer et al., } \\
2020)\end{array}$ & $\begin{array}{c}\text { COVID-19 Inflammatory Syndrome With Clinical Features } \\
\text { Resembling Kawasaki Disease }\end{array}$ & $\begin{array}{l}\text { Estados } \\
\text { Unidos } \\
\end{array}$ & Pediatrics & $\begin{array}{l}\text { Relato de } \\
\text { casos }\end{array}$ \\
\hline $\begin{array}{l}\text { (Toubiana et } \\
\text { al., 2020) }\end{array}$ & $\begin{array}{l}\text { Kawasaki-like multisystem inflammatory syndrome in } \\
\text { children during the covid-19 pandemic in Paris, France: } \\
\text { prospective observational study }\end{array}$ & França & $\mathrm{BMJ}$ & Observacional \\
\hline $\begin{array}{l}\text { (Vari et al., } \\
\text { 2020) }\end{array}$ & $\begin{array}{c}\text { Severe cardiac dysfunction in a patient with multisystem } \\
\text { inflammatory syndrome in children associated with } \\
\text { COVID-19: Retrospective diagnosis of a puzzling } \\
\text { presentation. A case report }\end{array}$ & $\begin{array}{l}\text { Estados } \\
\text { Unidos }\end{array}$ & $\begin{array}{l}\text { Progress in Pediatric } \\
\text { Cardiology }\end{array}$ & Relato de caso \\
\hline $\begin{array}{l}\text { (Verdoni et al., } \\
\text { 2020) }\end{array}$ & $\begin{array}{l}\text { An outbreak of severe Kawasaki-like disease at the Italian } \\
\text { epicentre of the SARS-CoV-2 epidemic: an observational } \\
\text { cohort study }\end{array}$ & Itália & The Lancet & $\begin{array}{l}\text { Estudo de } \\
\text { coorte }\end{array}$ \\
\hline $\begin{array}{l}\text { (Waltuch et } \\
\text { al., 2020) }\end{array}$ & $\begin{array}{c}\text { Features of COVID-19 post-infectious cytokine release } \\
\text { syndrome in children presenting to the emergency } \\
\text { department }\end{array}$ & $\begin{array}{l}\text { Estados } \\
\text { Unidos }\end{array}$ & $\begin{array}{l}\text { American Journal of } \\
\text { Emergency Medicine }\end{array}$ & Série de casos \\
\hline $\begin{array}{l}\text { (Whittaker et } \\
\text { al., 2020) }\end{array}$ & $\begin{array}{c}\text { Clinical Characteristics of } 58 \text { Children With a Pediatric } \\
\text { Inflammatory Multisystem Syndrome Temporally } \\
\text { Associated With SARS-CoV-2 }\end{array}$ & $\begin{array}{l}\text { Reino } \\
\text { Unido }\end{array}$ & JAMA & $\begin{array}{l}\text { Observacional } \\
\text { retrospectivo }\end{array}$ \\
\hline
\end{tabular}

Fonte: Autores.

O resultado das buscas monta um cenário composto por diversos países atingidos pela pandemia, dentre eles os Estados Unidos, Reino Unido, Itália, França, Brasil, Espanha, Índia, Israel, Arábia Saudita, Iran, Paquistão e República Tcheca. Importante ressaltar que não foi encontrado nenhum estudo referente ao tema de autoria Chinesa, ao que tudo indica, mesmo com a pandemia tendo origem na região, não houve relatos publicizados sobre o aumento no número de casos de KD ou surgimento de casos de MIS-C.

A Tabela 2 traz uma síntese dos principais resultados encontrados nos estudos incluídos na revisão, a soma de todas as amostras relatadas nos artigos selecionados totalizou um número de 385 pacientes, sendo a maioria do sexo masculino $(\mathrm{n}=$ $226 / 58,8 \%$ ) com idade média de 8,8 anos. Quanto à etnia, apenas 160 pacientes foram efetivamente identificados com maior 
contingente de pacientes afrodescendentes $(\mathrm{n}=56 / 35 \%)$, seguido de pacientes brancos $(\mathrm{n}=30 / 18,8 \%)$, asiáticos $(\mathrm{n}=28 / 17,5$ \%), hispânicos $(n=18 / 11,2 \%)$ e outros $(n=23 / 14,4 \%)$.

Observando o quantitativo de pacientes que apresentaram comorbidades $(n=80 / 20,8 \%$ ), podemos destacar maior frequência de sobrepeso e/ou obesidade $(n=31 / 38,7 \%)$, doenças respiratórias como asma e rinite $(n=27 / 33,7 \%)$, neoplasia e lúpus $(n=8 / 10 \%)$, doenças cardíacas ou hematológicas $(n=6 / 7,5 \%)$, doenças neurológicas como epilepsia e paralisia cerebral $(\mathrm{n}=3 / 3,8 \%)$, hipertireoidismo e doença renal $(\mathrm{n}=2 / 2,5 \%)$.

Todos os pacientes investigados em seus respectivos estudos foram testados positivos para o vírus Sars-Cov-2, seja pela transcrição reversa e reação em cadeia da polimerase (RT-PCR) ou através da sorologia de imunoensaio enzimático (ELISA). No que tange o diagnóstico diferencial resultante das manifestações inflamatórias, identificamos maior ocorrência da Síndrome inflamatória multissistêmica pediátrica - MIS-C com ( $\mathrm{n}=257 / 66,8 \%)$, a doença de Kawasaki foi diagnosticada em ( $n=105 / 27,3 \%)$ crianças, apenas $(n=14 / 3,6 \%)$ apresentaram a doença de Kawasaki atípica, e $(n=09 / 2,3 \%)$ a Síndrome do choque tóxico (TSS).

O tempo médio de hospitalização foi de 9 dias $(3-17$ dias), dentre os procedimentos de suporte ventilatório realizados, a ventilação mecânica invasiva foi a mais ostensiva $(n=113 / 29 \%)$, seguido da ventilação não invasiva $(\mathrm{n}=$ $50 / 13 \%)$, da suplementação de oxigênio $(n=16 / 4 \%)$ e da oxigenação por membrana extracorpórea $(n=12 / 3 \%)$. Apesar da gravidade das síndromes, a taxa de desfechos positivos foi superior: altas $(n=339 / 88 \%)$, óbitos $(n=15 / 3,9 \%)$, sem relato $(n=$ $30 / 7,8 \%)$ e indeterminado $(n=01 / 0,3 \%)$.

Tabela 2 - Síntese dos resultados.

\begin{tabular}{|c|c|c|c|c|c|c|c|c|}
\hline Autores & (n) & Idade & $\begin{array}{c}\text { Teste } \\
\text { Sars-Cov-2 } \\
\text { (Positivo) }\end{array}$ & $\begin{array}{l}\text { Diagnóstico } \\
\text { Diferencial }\end{array}$ & Apresentação Clínica & $\begin{array}{l}\text { Suporte } \\
\text { Pulmonar }\end{array}$ & $\begin{array}{c}\text { Tempo } \\
\text { de hospit. }\end{array}$ & Desfecho \\
\hline $\begin{array}{l}\text { (Alnashri et al., } \\
\text { 2020) }\end{array}$ & 01 & $16 \mathrm{a}$ & Sorologia & MIS-C & $\begin{array}{l}\text { Febre, Conjuntivite bilateral, Erupção } \\
\text { cutânea, Edema de extremidades, Fissura } \\
\text { labial, Dor abdominal, Diarreia, Vômitos, Dor } \\
\text { torácica, Hipotensão, Disfuncão cardíaca. }\end{array}$ & Não & 5 dias & Alta \\
\hline $\begin{array}{l}\text { (Bahrami et al., } \\
\text { 2020) }\end{array}$ & 01 & $5 \mathrm{a}$ & Sorologia & $\mathrm{KD}$ & $\begin{array}{l}\text { Febre, Conjuntivite bilateral, Erupção } \\
\text { cutânea, Edema de extremidades, Edema } \\
\text { periorbital, Fissura labial, Dor abdominal, } \\
\text { Diarreia, Vômitos, Taquicardia, Hipotensão, } \\
\text { Dispneia. }\end{array}$ & Não & 3 dias & Alta \\
\hline $\begin{array}{l}\text { (Belhadjer et } \\
\text { al., 2020) }\end{array}$ & 35 & M: 10 a & $\begin{array}{l}\text { Sorologia / } \\
\text { RT - PCR }\end{array}$ & MIS-C & $\begin{array}{l}\text { Febre }(\mathrm{n}=35) \text {, Linfadenopatia cervical }(\mathrm{n}= \\
21) \text {, Erupção cutânea }(\mathrm{n}=20) \text {, Dor abdominal } \\
(\mathrm{n}=29) \text {, Diarreia }(\mathrm{n}=29) \text {, Vômitos }(\mathrm{n}=29) \text {, } \\
\text { Rinorreia }(\mathrm{n}=15) \text {, Dispneia }(\mathrm{n}=23) \text {, Dor no } \\
\text { peito }(\mathrm{n}=6) \text {. }\end{array}$ & $\begin{array}{l}\text { ECMO (10) } \\
\text { VNI (11) } \\
\text { VMI }(22)\end{array}$ & M: 7 dias & Alta (35) \\
\hline $\begin{array}{l}\text { (Burger et al., } \\
\text { 2020) }\end{array}$ & 01 & $6 \mathrm{a}$ & RT- PCR & MIS-C & $\begin{array}{l}\text { Febre, Conjuntivite bilateral, Linfadenopatia } \\
\text { cervical, Erupção cutânea, Edema de } \\
\text { extremidades, Fissura labial, Dor abdominal, } \\
\text { Falta de apetite, Taquicardia, Hipotensão, } \\
\text { Dispneia, Fadiga, Disfunção cardíaca. }\end{array}$ & $\begin{array}{l}\text { ECMO } \\
\text { VMI }\end{array}$ & 6 dias & Alta \\
\hline $\begin{array}{l}\text { (Capone et al., } \\
\text { 2020) }\end{array}$ & 33 & M: 8,6 a & $\begin{array}{l}\text { Sorologia / } \\
\text { RT-PCR }\end{array}$ & MIS-C & $\begin{array}{l}\text { Febre }(n=33) \text {, Dor de cabeça }(n=19) \text {, } \\
\text { letargia }(n=19) \text {, Dor abdominal }(n=32), \\
\text { Diarreia }(n=32) \text {, Vômitos }(n=32) \text {, Tosse }(n \\
=17) \text {, Congestão nasal }(n=17) \text {, Dispneia }(n= \\
\text { 17), Choque }(n=25) \text {, Lesão renal aguda }(n= \\
\text { 23), Lesão hepática aguda }(n=7) \text {, Disfunção } \\
\text { cardíaca }(n=19) \text {. }\end{array}$ & $\begin{array}{l}\text { VMI (6) } \\
\text { O2 / VNI } \\
\quad(17)\end{array}$ & M: 4 dias & Alta (33) \\
\hline $\begin{array}{l}\text { (Carter et al., } \\
\text { 2020) }\end{array}$ & 25 & M: $12,5 \mathrm{a}$ & $\begin{array}{l}\text { Sorologia / } \\
\text { RT-PCR }\end{array}$ & MIS-C & $\begin{array}{l}\text { Febre }(\mathrm{n}=25) \text {, Conjuntivite bilateral }(\mathrm{n}=10) \text {, } \\
\text { Linfadenopatia cervical }(\mathrm{n}=4) \text {, Erupção } \\
\text { cutânea }(\mathrm{n}=12) \text {, Dor abdominal }(\mathrm{n}=18), \\
\text { Diarreia }(\mathrm{n}=18) \text {, Vômitos }(\mathrm{n}=18), \\
\text { Taquicardia }(\mathrm{n}=6) \text {, Dispneia }(\mathrm{n}=4) \text {, } \\
\text { Pneumonia }(\mathrm{n}=7) \text {, Embolia pulmonar }(\mathrm{n}= \\
\text { 2). }\end{array}$ & VMI (2) & M: 8 dias & $S / R$ \\
\hline $\begin{array}{l}\text { (Cazzaniga et } \\
\text { al., 2020) }\end{array}$ & 01 & $6 \mathrm{a}$ & $\mathrm{RT}-\mathrm{PCR}$ & $\mathrm{KD}-\mathrm{A}$ & $\begin{array}{l}\text { Febre, Conjuntivite bilateral, Linfadenopatia } \\
\text { cervical, Erupção cutânea, Diarreia, Vômitos, } \\
\text { Dispneia. }\end{array}$ & Não & $S / R$ & Alta \\
\hline $\begin{array}{l}\text { (Chiotos et al., } \\
2020)\end{array}$ & 06 & M: 8,6 a & $\begin{array}{l}\text { Sorologia / } \\
\text { RT-PCR }\end{array}$ & MIS-C & $\begin{array}{l}\text { Febre }(\mathrm{n}=6) \text {, Conjuntivite bilateral }(\mathrm{n}=2) \text {, } \\
\text { Erupção cutânea }(\mathrm{n}=2), \text { Edema de }\end{array}$ & $\begin{array}{l}\text { VMI (3) } \\
\text { VNI (2) }\end{array}$ & $\begin{array}{c}\text { M: } 10 \\
\text { dias }\end{array}$ & $\begin{array}{l}\text { Alta (5) } \\
\text { Interno }\end{array}$ \\
\hline
\end{tabular}




\begin{tabular}{|c|c|c|c|c|c|c|c|c|}
\hline & & & & & $\begin{array}{l}\text { extremidades }(\mathrm{n}=2) \text {, Fissura Labial }(\mathrm{n}=3), \\
\text { Dor abdominal }(\mathrm{n}=5), \text { Diarreia }(\mathrm{n}=4), \\
\text { Vômitos }(\mathrm{n}=5) \text {, Dispneia }(\mathrm{n}=4) \text {, Hipotensão } \\
(\mathrm{n}=7) \text {, Agitação }(\mathrm{n}=2), \text { Dor de cabeça }(\mathrm{n}= \\
\text { 1), parada respiratória }(\mathrm{n}=4) \text {, Choque }(\mathrm{n}= \\
\text { 6). }\end{array}$ & & & (1) \\
\hline $\begin{array}{l}\text { (Chiu et al., } \\
\text { 2020) }\end{array}$ & 01 & $10 \mathrm{a}$ & RT- PCR & $\mathrm{KD}$ & $\begin{array}{l}\text { Febre, Conjuntivite Bilateral, Linfadenopatia } \\
\text { Cervical, Erupção Cutânea, Fissura Labial, } \\
\text { Diarreia, Taquicardia, Hipotensão, Tosse, } \\
\text { Fadiga, Disfunção cardíaca. }\end{array}$ & Não & $\mathrm{S} / \mathrm{R}$ & $\begin{array}{l}\text { Indetermi } \\
\text { nado }\end{array}$ \\
\hline $\begin{array}{c}\text { (De Paulis et al., } \\
\text { 2020) }\end{array}$ & 01 & $4 \mathrm{a}$ & $\begin{array}{l}\text { Sorologia / } \\
\text { RT-PCR }\end{array}$ & MIS-C & \begin{tabular}{|l|l|} 
Febre, Erupção Cutânea, Edema De \\
Extremidades, Edema Periorbital, Fissura \\
Labial, Vômitos, Sonolência, Fadiga.
\end{tabular} & VMI & 17 dias & Alta \\
\hline $\begin{array}{l}\text { (Farias et al., } \\
\text { 2020) }\end{array}$ & 01 & $7 \mathrm{~m}$ & RT- PCR & MIS-C & $\begin{array}{l}\text { Febre, Diarreia, Vômitos, Tosse, Agitação, } \\
\text { Letargia, Hipóxia, Apneia, Convulsão, } \\
\text { Taquicardia, Hipotensão, Cianose. } \\
\end{array}$ & VMI / O2 & 2 dias & Óbito \\
\hline $\begin{array}{l}\text { (de Farias et al., } \\
\text { 2020) }\end{array}$ & 11 & M: 5 a & RT- PCR & KD / TSS & $\begin{array}{l}\text { "As principais apresentações clínicas dessas } \\
11 \text { crianças com PMIS-TS foram: síndrome } \\
\text { do choque tóxico ( } 2 \text { casos), síndrome do } \\
\text { choque da doença de Kawasaki (5 casos) e } \\
\text { doença de Kawasaki (4)." }\end{array}$ & $\begin{array}{l}\text { VMI (7) } \\
\text { VNI (3) }\end{array}$ & 5 dias & $\begin{array}{l}\text { Alta (9) } \\
\text { Óbitos } \\
(2)\end{array}$ \\
\hline (Ng et al., 2020) & 03 & $\begin{array}{c}13,16,17 \\
\text { a }\end{array}$ & Sorologia & MIS-C / KD & $\begin{array}{l}\text { Febre }(\mathrm{n}=3) \text {, Conjuntivite bilateral }(\mathrm{n}=2), \\
\text { Erupção cutânea }(\mathrm{n}=2) \text {, Fissura Labial }(\mathrm{n}= \\
\text { 1), Dor abdominal }(\mathrm{n}=3) \text {, Diarreia }(\mathrm{n}=3), \\
\text { Vômitos }(\mathrm{n}=3) \text {, Dispneia }(\mathrm{n}=2) \text {, Hipotensão } \\
(\mathrm{n}=3) \text {, Agitação }(\mathrm{n}=2) \text {, Dor de cabeça }(\mathrm{n}= \\
\text { 1), Taquicardia }(\mathrm{n}=3) \text {, Confusão }(\mathrm{n}=1) \text {. }\end{array}$ & $\begin{array}{l}\text { VMI (1) } \\
\text { VNI (1) } \\
\text { O2 (1) }\end{array}$ & 14 dias & Alta (3) \\
\hline $\begin{array}{l}\text { (Greene et al., } \\
\text { 2020) }\end{array}$ & 01 & $11 \mathrm{a}$ & RT-PCR & $\mathrm{KD} / \mathrm{TSS}$ & $\begin{array}{l}\text { Febre, Erupção Cutânea, Dor Abdominal, } \\
\text { Taquicardia, Hipotensão, Dispneia, Disfunção } \\
\text { cardíaca. }\end{array}$ & Não & $\mathrm{S} / \mathrm{R}$ & Alta \\
\hline $\begin{array}{l}\text { (Grimaud et al., } \\
\text { 2020) }\end{array}$ & 20 & $\mathrm{M}: 10 \mathrm{a}$ & $\begin{array}{l}\text { Sorologia / } \\
\text { RT-PCR }\end{array}$ & MIS-C & $\begin{array}{l}\text { Febre }(\mathrm{n}=20) \text {, Conjuntivite Bilateral }(\mathrm{n}=6), \\
\text { Erupção Cutânea }(\mathrm{n}=10) \text {, Dor Abdominal }(\mathrm{n} \\
=20) \text {, Taquicardia }(\mathrm{n}=20) \text {, Hipotensão }(\mathrm{n}= \\
\text { 20), Queilite }(\mathrm{n}=5) \text {, Adenite }(\mathrm{n}=2)\end{array}$ & $\begin{array}{l}\text { VMI (8) } \\
\text { VNI (11) } \\
\text { O2 (1) }\end{array}$ & 4 dias & Alta (20) \\
\hline $\begin{array}{l}\text { (Heidemann et } \\
\text { al., 2020) }\end{array}$ & 03 & $5,6,7$ a & Sorologia & MIS-C & $\begin{array}{l}\text { Febre }(\mathrm{n}=3) \text {, Conjuntivite Bilateral }(\mathrm{n}=2), \\
\text { Linfadenopatia Cervical }(\mathrm{n}=2) \text {, Erupção } \\
\text { Cutânea }(\mathrm{n}=2) \text {, Edema De Extremidades }(\mathrm{n}= \\
\text { 1), Fissura Labial }(\mathrm{n}=3) \text {. }\end{array}$ & $\begin{array}{l}\text { O2 (1) } \\
\text { VMI (1) }\end{array}$ & 7 dias & Alta (3) \\
\hline $\begin{array}{l}\text { (Jones et al., } \\
\text { 2020) }\end{array}$ & 01 & $6 \mathrm{~m}$ & RT- PCR & $\mathrm{KD}$ & $\begin{array}{l}\text { Febre, Conjuntivite Bilateral, Linfadenopatia } \\
\text { Cervical, Erupção Cutânea, Edema De } \\
\text { Extremidades, Dor Abdominal, Taquicardia, } \\
\text { Dispneia, Tosse, Agitação. }\end{array}$ & Não & $\mathrm{S} / \mathrm{R}$ & Alta \\
\hline $\begin{array}{l}\text { (Kaushik et al., } \\
\text { 2020) }\end{array}$ & 33 & M: $10 \mathrm{a}$ & $\begin{array}{l}\text { Sorologia / } \\
\text { RT - PCR }\end{array}$ & MIS-C & $\begin{array}{l}\text { Febre }(\mathrm{n}=31) \text {, Conjuntivite Bilateral }(\mathrm{n}= \\
\text { 12), Erupção Cutânea }(\mathrm{n}=14), \text { Dor } \\
\text { Abdominal }(\mathrm{n}=21) \text {, Diarreia }(\mathrm{n}=16) \text {, } \\
\text { Vômitos }(\mathrm{n}=23) \text {, Hipotensão }(\mathrm{n}=21) \text {, } \\
\text { Dispneia }(\mathrm{n}=11) \text {, Tonturas }(\mathrm{n}=3) \text {, Derrame } \\
\text { pericárdico }(\mathrm{n}=15) \text {. }\end{array}$ & $\begin{array}{l}\text { VMI (5) } \\
\text { ECMO (1) }\end{array}$ & 7 dias & $\begin{array}{l}\text { Alta (32) } \\
\text { Óbito (1) }\end{array}$ \\
\hline $\begin{array}{l}\text { (Kest et al., } \\
\text { 2020) }\end{array}$ & 03 & $6,9,10 \mathrm{a}$ & RT- PCR & MIS-C & $\begin{array}{l}\text { Febre }(\mathrm{n}=3) \text {, Conjuntivite Bilateral }(\mathrm{n}=3), \\
\text { Erupção Cutânea }(\mathrm{n}=2) \text {, Dor Abdominal }(\mathrm{n}= \\
\text { 2), Diarreia }(\mathrm{n}=3) \text {, Vômitos }(\mathrm{n}=2), \\
\text { Hipotensão }(\mathrm{n}=2) \text {, Dispneia }(\mathrm{n}=2) \text {, Dor de } \\
\text { cabeça }(\mathrm{n}=1) \text {. }\end{array}$ & VMI (2) & 11 dias & Alta (3) \\
\hline $\begin{array}{l}\text { (Klocperk et al., } \\
\text { 2020) }\end{array}$ & 01 & $8 \mathrm{a}$ & $\begin{array}{l}\text { Sorologia / } \\
\text { RT - PCR }\end{array}$ & MIS-C & $\begin{array}{l}\text { Febre, Erupção Cutânea, Edema De } \\
\text { Extremidades, Dor Abdominal, Diarreia, Dor } \\
\text { de cabeça. }\end{array}$ & Não & 15 dias & Alta \\
\hline $\begin{array}{l}\text { (Licciardi et al., } \\
\text { 2020) }\end{array}$ & 02 & $7,12 \mathrm{a}$ & Sorologia & MIS-C & $\begin{array}{l}\text { Febre }(\mathrm{n}=2) \text {, Conjuntivite Bilateral }(\mathrm{n}=2), \\
\text { Linfadenopatia Cervical }(\mathrm{n}=1) \text {, Erupção } \\
\text { Cutânea }(\mathrm{n}=2) \text {, Edema De Extremidades }(\mathrm{n}= \\
\text { 1), Fissura Labial }(\mathrm{n}=1) \text {, Dor Abdominal }(\mathrm{n} \\
=2), \text { Diarreia }(\mathrm{n}=2), \text { Vômitos }(\mathrm{n}=2), \\
\text { Faringite }(\mathrm{n}=1), \text { Taquicardia }(\mathrm{n}=1), \text { Dor } \\
\text { torácica, Hipotensão }(\mathrm{n}=1) \text {, Dispneia }(\mathrm{n}=1), \\
\text { Derrame pleural }(\mathrm{n}=1) \text {, Disfunção cardíaca } \\
(\mathrm{n}=1) \text {. }\end{array}$ & VNI (1) & $\mathrm{S} / \mathrm{R}$ & Alta (2) \\
\hline $\begin{array}{l}\text { (Mahajan et al., } \\
\text { 2020) } \\
\end{array}$ & 01 & $8 a$ & Sorologia & MIS-C & $\begin{array}{l}\text { Febre, Dor Abdominal, Falta de Apetite, } \\
\text { Taquicardia, Disfunção cardíaca. }\end{array}$ & VMI & 14 dias & Alta \\
\hline $\begin{array}{l}\text { (Mamishi et al., } \\
\text { 2020) }\end{array}$ & 45 & M: 7 a & $\begin{array}{l}\text { Sorologia / } \\
\text { RT-PCR }\end{array}$ & MIS-C / KD & $\begin{array}{l}\text { Febre }(\mathrm{n}=41) \text {, Conjuntivite Bilateral }(\mathrm{n}= \\
\text { 23), Linfadenopatia Cervical }(\mathrm{n}=9) \text {, Erupção } \\
\text { Cutânea }(\mathrm{n}=24) \text {, Edema De Extremidades }(\mathrm{n} \\
=18) \text {, Dor Abdominal }(\mathrm{n}=26) \text {, Diarreia }(\mathrm{n}= \\
\text { 16), Vômitos }(\mathrm{n}=23), \text { Dispneia }(\mathrm{n}=8), \\
\text { Tosse }(\mathrm{n}=16), \text { Fadiga }(\mathrm{n}=11) \text {, Disfunção } \\
\text { cardíaca }(\mathrm{n}=14) \text {, Derrame pleural }(\mathrm{n}=8), \\
\text { Ascite }(\mathrm{n}=5) \text {, Insuficiência Renal Aguda }(\mathrm{n}= \\
\text { 13). }\end{array}$ & $\mathrm{S} / \mathrm{R}$ & $\mathrm{S} / \mathrm{R}$ & $\begin{array}{l}\text { Alta (40) } \\
\text { Óbito (5) }\end{array}$ \\
\hline
\end{tabular}




\begin{tabular}{|c|c|c|c|c|c|c|c|c|}
\hline $\begin{array}{l}\text { (Masih et al., } \\
2020)\end{array}$ & 01 & $9 \mathrm{a}$ & RT - PCR & MIS-C & $\begin{array}{l}\text { Febre, Dor Abdominal, Diarreia, Taquicardia, } \\
\text { Tosse, Dor de cabeça. }\end{array}$ & Não & 12 dias & Alta \\
\hline $\begin{array}{l}\text { (Moazzam et } \\
\text { al., 2020) }\end{array}$ & 01 & 8 a & RT - PCR & MIS-C & $\begin{array}{l}\text { Febre, Dor Abdominal, Vômitos, Taquicardia, } \\
\text { Hipotensão. }\end{array}$ & Não & 7 dias & Alta \\
\hline $\begin{array}{l}\text { (Moraleda et al., } \\
\text { 2020) }\end{array}$ & 31 & M: 7,6 a & RT- PCR & MIS-C / KD & $\begin{array}{l}\text { Febre }(\mathrm{n}=30) \text {, Conjuntivite Bilateral }(\mathrm{n}= \\
23), \text { Linfadenopatia Cervical }(\mathrm{n}=31), \\
\text { Erupção Cutânea }(\mathrm{n}=23) \text {, Dor Abdominal }(\mathrm{n} \\
=27) \text {, Diarreia }(\mathrm{n}=27) \text {, Vômitos }(\mathrm{n}=27), \\
\text { Hipotensão }(\mathrm{n}=15) \text {, Dispneia }(\mathrm{n}=30) \text {, Tosse } \\
(\mathrm{n}=31) \text {, Dor de cabeça }(\mathrm{n}=29) \text {, Fadiga }(\mathrm{n}= \\
\text { 15), Disfunção cardíaca }(\mathrm{n}=19) \text {, Dor de } \\
\text { garganta }(\mathrm{n}=31) \text {. }\end{array}$ & VMI (6) & $\mathrm{S} / \mathrm{R}$ & $\begin{array}{l}\text { Alta (30) } \\
\text { Óbito (1) }\end{array}$ \\
\hline $\begin{array}{l}\text { (Nguyen et al., } \\
2020 \text { ) }\end{array}$ & 01 & $10 \mathrm{a}$ & Sorologia & MIS-C & Febre, Dor Abdominal, Diarreia, Vômitos. & Não & 4 dias & Alta \\
\hline $\begin{array}{l}\text { (Pouletty et al., } \\
\text { 2020) }\end{array}$ & 16 & M: $10 \mathrm{a}$ & $\begin{array}{l}\text { Sorologia / } \\
\text { RT-PCR }\end{array}$ & $\mathrm{KD}$ & $\begin{array}{l}\text { Febre }(\mathrm{n}=16) \text {, Conjuntivite Bilateral }(\mathrm{n}= \\
\text { 15), Linfadenopatia Cervical }(\mathrm{n}=6) \text {, Erupção } \\
\text { Cutânea }(\mathrm{n}=13) \text {, Edema De Extremidades }(\mathrm{n} \\
=11), \text { Fissura Labial }(\mathrm{n}=14), \quad \text { Dor } \\
\text { Abdominal }(\mathrm{n}=13), \text { Diarreia }(\mathrm{n}=13), \\
\text { Vômitos }(\mathrm{n}=13) \text {, Dispneia }(\mathrm{n}=2) \text {, Disfunção } \\
\text { cardíaca }(\mathrm{n}=11) \text {, Falha Hemodinâmica }(\mathrm{n}= \\
\text { 11). }\end{array}$ & $\begin{array}{l}\text { VMI (2) } \\
\text { VNI (3) } \\
\text { O2 (4) }\end{array}$ & 14 dias & Alta (16) \\
\hline $\begin{array}{l}\text { (Pereira et al., } \\
\text { 2020) }\end{array}$ & 06 & M: 7,7 a & $\begin{array}{l}\text { Sorologia / } \\
\text { RT-PCR }\end{array}$ & MIS-C & $\begin{array}{l}\text { Febre }(\mathrm{n}=6) \text {, Dor Abdominal }(\mathrm{n}=4), \\
\text { Diarreia }(\mathrm{n}=4) \text {, Vômitos }(\mathrm{n}=4) \text {, Hipotensão } \\
(\mathrm{n}=3) \text {, Dispneia }(\mathrm{n}=4) \text {, Tosse }(\mathrm{n}=5), \\
\text { Pneumonia }(\mathrm{n}=3) \text { Hipoxemia }(\mathrm{n}=5), \\
\text { Disfunção cardíaca }(\mathrm{n}=6) \text {. }\end{array}$ & $\begin{array}{l}\text { VMI (5) } \\
\text { O2 (6) }\end{array}$ & 6 dias & $\begin{array}{c}\text { Alta (2) } \\
\text { Óbito (4) }\end{array}$ \\
\hline $\begin{array}{c}\text { (Raut et al., } \\
2020)\end{array}$ & 01 & $5 \mathrm{~m}$ & RT - PCR & $\mathrm{KD}-\mathrm{A}$ & $\begin{array}{|lll|}\begin{array}{l}\text { Febre, Conjuntivite } \\
\text { Cutânea. }\end{array} & \text { Bilateral, Erupção } \\
\end{array}$ & Não & 14 dias & Alta \\
\hline $\begin{array}{l}\text { (Regev et al., } \\
\quad 2020)\end{array}$ & 01 & $16 \mathrm{a}$ & Sorologia & $\mathrm{KD}-\mathrm{A}$ & $\begin{array}{l}\text { Febre, Conjuntivite Bilateral, Erupção } \\
\text { Cutânea, Dor Abdominal, Fadiga, Faringite, } \\
\text { Disfunção cardíaca, Clónus, Derrame pleural, } \\
\text { Fraqueza muscular. }\end{array}$ & VMI & $\mathrm{S} / \mathrm{R}$ & Alta \\
\hline $\begin{array}{l}\text { (Sampaio et al., } \\
\text { 2020) }\end{array}$ & 01 & 4 a & Sorologia & MIS-C & $\begin{array}{l}\text { Febre, Erupção Cutânea, Edema } \\
\begin{array}{l}\text { Extremidades, Edema } \\
\text { Abdominal, Falta de Apetite, Disfunção } \\
\text { cardíaca. }\end{array} \\
\end{array}$ & $\mathrm{O} 2$ & 9 dias & Alta \\
\hline $\begin{array}{l}\text { (Spencer et al., } \\
\text { 2020) }\end{array}$ & 02 & $7,11 \mathrm{a}$ & RT- PCR & $\mathrm{KD}$ & $\begin{array}{l}\text { Febre }(\mathrm{n}=2) \text {, Conjuntivite Bilateral }(\mathrm{n}=2), \\
\text { Erupção Cutânea }(\mathrm{n}=2) \text {, Edema De } \\
\begin{array}{l}\text { Extremidades }(\mathrm{n}=1), \\
\text { Derrame pericárdico }(\mathrm{n}=1) \text {, Disfunção } \\
\text { cardíaca }(\mathrm{n}=2) \text {. }\end{array} \\
\end{array}$ & Não & 14 dias & Alta (2) \\
\hline $\begin{array}{l}\text { (Toubiana et al., } \\
\text { 2020) }\end{array}$ & 21 & M: 7,9 a & $\begin{array}{l}\text { Sorologia / } \\
\text { RT - PCR }\end{array}$ & $\mathrm{KD}$ & $\begin{array}{l}\text { Febre }(\mathrm{n}=11) \text {, Conjuntivite Bilateral }(\mathrm{n}= \\
\text { 17), Linfadenopatia Cervical }(\mathrm{n}=12), \\
\text { Erupção Cutânea }(\mathrm{n}=17) \text {, Edema De } \\
\text { Extremidades }(\mathrm{n}=10) \text {, Fissura Labial }(\mathrm{n}= \\
\text { 16), Dor Abdominal }(\mathrm{n}=21) \text {, Diarreia }(\mathrm{n}= \\
\text { 21), Vômitos }(\mathrm{n}=21) \text {, Agitação }(\mathrm{n}=12), \\
\text { Disfunção cardíaca }(\mathrm{n}=16) \text {. }\end{array}$ & VMI (11) & 8 dias & Alta (21) \\
\hline $\begin{array}{l}\text { (Vari et al., } \\
\text { 2020) }\end{array}$ & 01 & $14 \mathrm{a}$ & Sorologia & MIS-C & $\begin{array}{l}\text { Febre, Erupção Cutânea, Dor Abdominal, } \\
\text { Diarreia, Hipotensão, Dispneia, Fadiga, } \\
\text { Disfunção cardíaca. }\end{array}$ & VMI & 12 dias & Alta \\
\hline $\begin{array}{l}\text { (Verdoni et al., } \\
\text { 2020) }\end{array}$ & 10 & M: 7,5 a & RT-PCR & $\mathrm{KD} / \mathrm{KD}-\mathrm{A}$ & $\begin{array}{l}\text { Febre }(\mathrm{n}=5) \text {, Conjuntivite Bilateral }(\mathrm{n}=7), \\
\text { Linfadenopatia Cervical }(\mathrm{n}=1) \text {, Erupção } \\
\text { Cutânea }(\mathrm{n}=7) \text {, Edema De Extremidades }(\mathrm{n}= \\
\text { 5), Fissura Labial }(\mathrm{n}=6) \text {, Diarreia }(\mathrm{n}=4), \\
\text { Hipotensão }(\mathrm{n}=5) \text {, Disfunção cardíaca }(\mathrm{n}= \\
\text { 2). }\end{array}$ & Não & $\mathrm{S} / \mathrm{R}$ & Alta (10) \\
\hline $\begin{array}{l}\text { (Waltuch et al., } \\
\text { 2020) }\end{array}$ & 04 & M: 10 a & Sorologia & $\begin{array}{l}\text { KD - A / } \\
\text { TSS }\end{array}$ & $\begin{array}{l}\text { Febre }(\mathrm{n}=4) \text {, Conjuntivite Bilateral }(\mathrm{n}=3), \\
\text { Linfadenopatia Cervical }(\mathrm{n}=12) \text {, Erupção } \\
\text { Cutânea }(\mathrm{n}=3) \text {, Fissura Labial }(\mathrm{n}=1) \text {, Dor } \\
\text { Abdominal }(\mathrm{n}=3) \text {, Diarreia }(\mathrm{n}=3) \text {, Vômitos } \\
(\mathrm{n}=3) \text {, Disfunção cardíaca }(\mathrm{n}=2) \text {, Fadiga }(\mathrm{n} \\
=2) \text {, Tosse }(\mathrm{n}=2) \text {, Dor de cabeça }(\mathrm{n}=1), \\
\text { Dispneia }(\mathrm{n}=2) \text {, Taquicardia }(\mathrm{n}=1),\end{array}$ & $\begin{array}{l}\text { VMI (1) } \\
\text { VNI (1) }\end{array}$ & $S / R$ & $\mathrm{~S} / \mathrm{R}$ \\
\hline $\begin{array}{l}\text { (Whittaker et } \\
\text { al., 2020) }\end{array}$ & 58 & M: 9 a & $\begin{array}{l}\text { Sorologia / } \\
\text { RT-PCR }\end{array}$ & MIS-C & $\begin{array}{l}\text { Febre }(\mathrm{n}=58) \text {, Conjuntivite Bilateral }(\mathrm{n}= \\
\text { 26), Linfadenopatia Cervical }(\mathrm{n}=9) \text {, Erupção } \\
\text { Cutânea }(\mathrm{n}=30) \text {, Edema De Extremidades }(\mathrm{n} \\
=9) \text {, Dor Abdominal }(\mathrm{n}=31) \text {, Diarreia }(\mathrm{n}= \\
\text { 30), Vômitos }(\mathrm{n}=26) \text {, Hipotensão }(\mathrm{n}=15), \\
\text { Dispneia }(\mathrm{n}=12) \text {, Tosse }(\mathrm{n}=31) \text {, Dor de } \\
\text { cabeça }(\mathrm{n}=15) \text {, Fadiga }(\mathrm{n}=15) \text {, Disfunção } \\
\text { cardíaca }(\mathrm{n}=19) \text {, Dor de garganta }(\mathrm{n}=31) \text {, } \\
\text { Choque }(\mathrm{n}=29) \text {, fissura labial }(\mathrm{n}=17) \text { lesão } \\
\text { renal aguda }(\mathrm{n}=19) \text {. }\end{array}$ & VMI (25) & $\mathrm{S} / \mathrm{R}$ & $\begin{array}{l}\text { Alta (57) } \\
\text { Óbito (1) }\end{array}$ \\
\hline
\end{tabular}

S/R - sem relato, M - média, a - anos, m - meses, RT-PCR - transcrição reversa e reação em cadeia da polimerase, MIS-C - Síndrome inflamatória 
multissistêmica pediátrica, KD - doença de Kawasaki, KD-A - doença de Kawasaki atípica, TSS - Síndrome do choque tóxico, VMI - ventilação mecânica invasiva, VNI - ventilação não invasiva, O2 - suplementação de oxigênio, ECMO - oxigenação por membrana extracorpórea. Fonte: Autores.

Os sinais e sintomas clínicos manifestaram-se nos mais diversos sistemas, contudo, o sintoma mais prevalente foi a febre alta acima de três dias ou mais $(\mathrm{n}=352 / 94 \%)$, outros sintomas como a conjuntivite bilateral não exudativa ( $\mathrm{n}=$ $163 / 44 \%)$ e a linfadenopatia cervical $(n=117 / 31 \%)$ foram bastante presentes. Entre os sintomas que acometeram a região nasal e orofaríngea, destacou-se as alterações dos lábios e/ou cavidade oral $(\mathrm{n}=67 / 18 \%)$, seguido de dor na garganta $(\mathrm{n}=$ $62 / 16,5 \%)$, rinorreia $(n=15 / 4 \%)$ e queilite $(n=5 / 1,3 \%)$.

Os sintomas gastrointestinais afetaram quase dois terços das crianças, sendo o mais presente a dor abdominal $(\mathrm{n}=$ $258 / 69 \%)$, seguido de vômito $(n=238 / 64 \%)$, diarreia $(n=235 / 63 \%)$ e a falta de apetite $(n=3 / 0,8 \%)$. Problemas respiratórios envolveram sintomas como a dispneia $(n=128 / 34 \%)$, tosse $(n=106 / 28 \%)$, pneumonia $(n=10 / 3 \%)$, derrame pleural $(n=$ $10 / 3 \%)$, parada respiratória $(n=4 / 1 \%)$ e embolia pulmonar $(n=2 / 0,5 \%)$.

Outro grupo de destaque na apresentação clínica foram os sintomas dermatológicos como a erupção cutânea polimórfica $(n=185 / 49 \%)$, edema de extremidades $(n=67 / 18 \%)$ e o edema periorbital e/ou facial $(n=03 / 0,8 \%)$. Além disso, problemas cardiológicos como disfunção cardíaca $(n=119 / 32 \%)$, hipotensão $(n=100 / 27 \%)$, taquicardia $(n=35 / 9 \%)$, derrame pericárdico $(n=16 / 4 \%)$, falha hemodinâmica $(n=11 / 3 \%)$ e dor no peito $(n=8 / 2 \%)$ foram condizentes com quadros de evolução mais graves. Outros sintomas menos pronunciados envolveram questões de cunho neurológico: dor de cabeça (n = 69/18\%), agitação e/ou confusão $(n=19 / 5 \%)$, tontura $(n=3 / 0,8 \%)$, sonolência $(n=1 / 0,3 \%)$, clónus muscular $(n=1 / 0,3 \%)$ e convulsão $(n=1 / 0,3 \%)$. Quanto a falha, lesão ou comprometimento de órgãos e sistemas vitais, obtivemos um quantitativo menor de pacientes: choque $(n=62 / 17 \%)$, lesão e/ou insuficiência renal aguda $(n=55 / 15 \%)$, lesão hepática aguda $(n=7 / 2 \%)$, ascite $(n=5 / 1,3 \%)$, fadiga $(n=48 / 13 \%)$ e fraqueza muscular $(n=1 / 0,3 \%)$.

\section{Discussão}

Esta revisão compila e compara dados de estudos que descrevem pacientes pediátricos acometidos por condições inflamatórias graves que foram comprovadamente contaminados pelo vírus SARS-CoV-2. A COVID-19 gera uma resposta imune inata desregulada através de tempestades de citocinas com possíveis quadros agravados por lesões endoteliais nos principais órgãos e sistemas. Os mecanismos desencadeadores das condições inflamatórias por intermédio do SARS-CoV-2 podem ocorrer via geração de armadilhas extracelulares por neutrófilos que tem função de aprisionar e eliminar o patógeno. A própria produção dessa rede extracelular pode gerar reações imunológicas de maneira não controlada, levando a uma resposta inflamatória sistêmica exagerada, semelhante a encontrada na síndrome inflamatória multissistêmica pediátrica (Mozzini \& Girelli, 2020).

Em abril de 2020 é publicado o primeiro relato de caso que aborda a possibilidade da associação entre a COVID-19 e a doença de Kawasaki (Jones et al., 2020). Posteriormente, em maio, foi observado um aumento em 30 vezes na incidência de doenças semelhantes a doença de Kawasaki na Itália (Verdoni et al., 2020). O aumento dessas síndromes inflamatórias parece seguir um padrão conforme a pandemia atinge outros países. As informações apontam para um possível fenômeno pósinfeccioso imunomediado, visto que o aumento de casos das síndromes inflamatórias se dá a partir de um intervalo entre duas e quatro semanas após o pico de incidência de casos da COVID-19 nas comunidades atingidas (CDC, 2020). As crianças analisadas, em geral, não apresentaram infecção aguda pelo SARS-CoV-2 durante a triagem na hospitalização. O atraso da condição inflamatória em relação à curva pandêmica, uma baixa proporção de casos da COVID-19 positivos por RT-PCR e uma alta de positivos para anticorpos sugere uma reação imunológica pós-viral como possível responsável pelo surgimento da síndrome inflamatória multissistêmica (Jiang et al., 2020).

O processo inflamatório desencadeado pelo vírus apresenta características semelhantes à doença de Kawasaki, muitos 
pacientes expostos ao vírus foram diagnosticados com a KD completa ou incompleta. Porém, é importante ressaltar que embora a KD compartilhe semelhanças com a MIS-C existem várias características epidemiológicas e clínicas que as distinguem. Esta revisão identificou que $67 \%$ dos pacientes investigados foram diagnosticados com a síndrome inflamatória multissistêmica pediátrica (MIS-C), epidemiologicamente, a KD atinge crianças abaixo de 5 anos de idade com maior prevalência entre os asiáticos, no entanto, identificamos um número maior de crianças afrodescendentes com idade superior aos 5 anos. As crianças negras e hispânicas têm sido mais atingidas pela COVID-19, determinantes sociais como moradia, instabilidade financeira, acesso a saúde e condições de trabalho podem amplificar a exposição desses grupos em situação de vulnerabilidade (Stokes et al., 2020).

Outro grupo que requer maior investigação é a população obesa, as crianças com comorbidades que foram mais afetadas apresentaram sobrepeso ou obesidade (39\%). A população obesa tem sofrido grande impacto com a pandemia da COVID-19 e o surgimento da MIS-C, o vírus SARS-CoV-2 tem ampla afinidade com a proteína ECA2 que é expressa em vários órgãos como pulmões, coração, rins, intestino, vasos sanguíneos e tecido adiposo. Consequentemente, indivíduos obesos podem ser capazes de hospedar e armazenar uma enorme carga viral, contribuindo para o agravamento da doença, elevando o risco de mortalidade (Iannelli et al., 2020).

Apesar de suas distinções, a KD e a MIS-C apresentam sinais e sintomas que podem se sobrepor, a febre (94\%), erupção cutânea polimórfica (49\%), conjuntivite bilateral não exudativa (44\%), a linfadenopatia cervical (31\%) e o edema de extremidades (18\%) são sintomas da KD clássica que se fizeram presentes também nos pacientes diagnosticados com MIS-C. Já os sintomas gastrintestinais como a dor abdominal (69\%), o vômito (64\%) e a diarreia (63\%) que são mais observados nos pacientes com MIS-C também acometeram o grupo com KD. Vale ressaltar que sintomas mais condizentes com o quadro agudo de COVID-19 como tosse (28\%), fadiga (13\%), rinorreia (4\%) e pneumonia (3\%) foram relatados com menor frequência. Os pacientes acometidos por MIS-C apresentaram evoluções mais graves, desenvolveram envolvimento de múltiplos órgãos com maiores anormalidades cardíacas (32\%), sinais de hipotensão (27\%) e quadros de choque (17\%), além de insuficiência renal aguda (15\%) e lesão hepática aguda (2\%). No geral, a maioria dos casos reportados como MIS-C apresentaram marcadores inflamatórios elevados (taxa de sedimentação de eritrócitos, proteína $\mathrm{C}$ reativa, ferritina, fibrinogênio, D-dímero, troponina e hipoalbuminemia) consistentes com os requeridos para diagnóstico da síndrome.

Um levantamento realizado nos Estados Unidos de março a julho de 2020 que investigou um total de 570 pacientes diagnosticados com MIS-C obteve resultados epidemiológicos e clínicos similares a este estudo. Os autores dividiram os pacientes em três grupos distintos: $\mathrm{O}$ primeiro grupo apresentou maior número de sistemas e órgãos envolvidos com destaque para os sintomas cardiovasculares e gastrointestinais. O segundo grupo incluiu pacientes com maior envolvimento do sistema respiratório indicando características principalmente da COVID-19 ou uma combinação de COVID-19 aguda e MIS-C. O terceiro grupo foi o que mais comumente preencheu os critérios da doença de Kawasaki completa além de apresentar a menor prevalência de complicações como choque, miocardite e danos cardíacos (Godfred-Cato et al., 2020).

Quanto ao manejo terapêutico farmacológico foi identificado comumente o uso de terapias padrão para o tratamento da KD, como o uso de imunoglobulina intravenosa - IVIG combinada ou não com o uso de corticosteroides, além de suporte inotrópico e anticoagulantes. Fármacos como anakinra, tocilizumabe e remdesivir foram menos utilizados, já o uso de antibióticos foi relatado em alguns estudos. O tempo médio de hospitalização foi de 9 dias, a maioria dos pacientes recebeu alta hospitalar (88\%). Contudo, um estudo obteve quase dois terços de óbitos em relação a sua amostra, o autor relata que através de uma análise univariada encontrou associação entre óbito e hipoxemia [OR 16,43; IC de 95\% 1,77-152,60; p = 0,014], SARS pediátrico [OR 37,86; IC de 95\% 3,85-372,77; $p=0,002$ ] e MIS-C [OR 58,00; IC 95\%6,39- 526,79; p = 0,0001] (Pereira et al., 2020). 


\section{Conclusão}

As informações apontam para a ocorrência de uma síndrome pós-viral que pode surgir no período entre duas e quatro semanas após a contaminação pelo vírus, os dados revelam a tendência para sintomas como febre e sintomas gastrointestinais que podem evoluir para quadros mais graves com complicações cardíacas, hipotensão, choque e óbito. Portanto, os impactos causados por essa nova conjuntura ainda são desconhecidos, decisões estratégicas no manejo da pandemia como a volta as aulas devem considerar a possibilidade no aumento do número de casos da MIS-C. Além disso, os serviços de saúde precisam aumentar a vigilância e capacitar os profissionais de saúde para lidarem com esse novo aspecto da COVID-19.

Fatores limitantes como o processo de subnotificação devem ser investigados ante a pequena quantidade de crianças que desencadearam a síndrome em detrimento do número de infectados pela COVID-19. Além disso, a maioria dos estudos publicados até o momento são relatos de casos e estudos observacionais, não sendo identificado nenhum ensaio clínico randomizado. O ineditismo do tema revela a necessidade do desenvolvimento de estudos aprofundados e a construção de protocolos clínicos. Portanto, o processo de elucidação dessa condição deverá ser contínuo com o transcorrer da pandemia e a divulgação desses achados deve ser maximizada pelos meios possíveis.

Diante do exposto, reiteramos a necessidade de novos estudos sobre o tema para que a ampla quantidade de dados seja sistematizada a fim de produzir novos conhecimentos que permitam subsidiar a construção de protocolos que priorizem a prevenção, a promoção de saúde e a reabilitação dos casos. Sugerimos que os futuros trabalhos busquem o desenvolvimento de instrumentos ou métodos que possam estratificar as diversas manifestações clínico-epidemiológicas dessa nova condição da COVID-19 no público pediátrico. A necessidade premente no avanço do domínio dessas novas informações deve tomar como ponto de partida o conhecimento da MIS-C, possíveis estratificações da doença, fatores de risco que possibilitem o agravo da condição de saúde e as consequências biopsicossociais a médio e longo prazo das crianças acometidas pela doença.

\section{Referências}

Agarwal, S., \& Agrawal, D. K. (2017). Kawasaki disease: Etiopathogenesis and novel treatment strategies. Expert Review of Clinical Immunology, 13(3), 247258. https://doi.org/10.1080/1744666X.2017.1232165

Alnashri, H., Aljohani, N., Tayeb, S., Rabie, N., AlBenayan, E., Alharthi, A., \& Samannodi, M. (2020). A challenging case of multisystem inflammatory syndrome in children related to coronavirus Disease-19 hospitalized under adult medical service. IDCases, 22 , e00957.

Bahrami, A., Vafapour, M., Moazzami, B., \& Rezaei, N. (2020). Hyperinflammatory shock related to COVID -19 in a patient presenting with multisystem inflammatory syndrome in children: First case from Iran. Journal of Paediatrics and Child Health, jpc.15048. https://doi.org/10.1111/jpc.15048

Belhadjer, Z., Méot, M., Bajolle, F., Khraiche, D., Legendre, A., Abakka, S., Auriau, J., Grimaud, M., Oualha, M., Beghetti, M., Wacker, J., Ovaert, C., Hascoet, S., Selegny, M., Malekzadeh-Milani, S., Maltret, A., Bosser, G., Giroux, N., Bonnemains, L., \& Bonnet, D. (2020). Acute Heart Failure in Multisystem Inflammatory Syndrome in Children in the Context of Global SARS-CoV-2 Pandemic. Circulation, 142(5), 429-436. https://doi.org/10.1161/CIRCULATIONAHA.120.048360

Brasil. (2020). Ministério da Saúde. Secretaria de Vigilância em Saúde. Boletim Epidemiológico, 51(43). https://www.gov.br/saude/ptbr/media/pdf/2020/novembro/03/boletim_epidemiologico_svs_43.pdf.

Burger, M. W., Moore, M. A., \& Wilburn, J. M. (2020). Case Report: Pediatric Patient with COVID-19 and Multisystem Inflammatory Syndrome in Children. Clinical Practice and Cases in Emergency Medicine, 4(4), 513.

Capone, C. A., Subramony, A., Sweberg, T., Schneider, J., Shah, S., Rubin, L., Schleien, C., Epstein, S., Johnson, J. C., Kessel, A., Misra, N., Mitchell, E., Palumbo, N., Rajan, S., Rocker, J., Williamson, K., \& Davidson, K. W. (2020). Characteristics, Cardiac Involvement, and Outcomes of Multisystem Inflammatory Syndrome of Childhood Associated with severe acute respiratory syndrome coronavirus 2 Infection. The Journal of Pediatrics, $224,141-145$. https://doi.org/10.1016/j.jpeds.2020.06.044

Carter, M. J., Fish, M., Jennings, A., Doores, K. J., Wellman, P., Seow, J., Acors, S., Graham, C., Timms, E., Kenny, J., Neil, S., Malim, M. H., Tibby, S. M., \& Shankar-Hari, M. (2020). Peripheral immunophenotypes in children with multisystem inflammatory syndrome associated with SARS-CoV-2 infection. Nature Medicine, 26(11), 1701-1707. https://doi.org/10.1038/s41591-020-1054-6

Cazzaniga, M., Baselli, L. A., Cimaz, R., Guez, S. S., Pinzani, R., \& Dellepiane, R. M. (2020). SARS-COV-2 Infection and Kawasaki Disease: Case Report of a Hitherto Unrecognized Association. Frontiers in pediatrics, 8.

CDC. (2020). Information for healthcare providers about multisystem inflammatory syndrome in children (MIS-C). https://www.cdc.gov/mis-c/hcp/ 
Chiotos, K., Bassiri, H., Behrens, E. M., Blatz, A. M., Chang, J., Diorio, C., Fitzgerald, J. C., Topjian, A., \& John, A. R. O. (2020). Multisystem Inflammatory Syndrome in Children During the Coronavirus 2019 Pandemic: A Case Series. Journal of the Pediatric Infectious Diseases Society, 9(3), 393-398. https://doi.org/10.1093/jpids/piaa069

Chiu, J. S., Lahoud-Rahme, M., Schaffer, D., Cohen, A., \& Samuels-Kalow, M. (2020). Kawasaki Disease Features and Myocarditis in a Patient with COVID19. Pediatric Cardiology, 41(7), 1526-1528. https://doi.org/10.1007/s00246-020-02393-0

de Farias, E., Pedro Piva, J., de Mello, M., do Nascimento, L., Costa, C. C., Machado, M., Rodrigues, T., Carvalho, R., Alves, M., Aires, L., Cotta, M., Pedreira, A., Saraty, S. B., Lima, M. C., \& Justino, M. (2020). Multisystem Inflammatory Syndrome Associated With Coronavirus Disease in Children: A Multi-centered Study in Belém, Pará, Brazil. The Pediatric infectious disease journal, 39(11), e374-e376. https://doi.org/10.1097/INF.0000000000002865

de Graeff, N., Groot, N., Ozen, S., Eleftheriou, D., Avcin, T., Bader-Meunier, B., Dolezalova, P., Feldman, B. M., Kone-Paut, I., Lahdenne, P., McCann, L., Pilkington, C., Ravelli, A., van Royen-Kerkhof, A., Uziel, Y., Vastert, B., Wulffraat, N., Kamphuis, S., Brogan, P., \& Beresford, M. W. (2019). European consensus-based recommendations for the diagnosis and treatment of Kawasaki disease - the SHARE initiative. Rheumatology, 58(4), 672-682. https://doi.org/10.1093/rheumatology/key344

De Paulis, M., Oliveira, D. B. L., Vieira, R. P., Pinto, I. C., Machado, R. R. G., Cavalcanti, M. P., Soares, C. P., de Araujo, A. M. P., Araujo, D. B., Bachi, A. L. L., Leal, F. B., Dorlass, E. G., Gilio, A. E., Durigon, E. L., \& Barreira, E. R. (2020). Multisystem Inflammatory Syndrome Associated With COVID-19 With Neurologic Manifestations in a Child: A Brief Report. Pediatric Infectious Disease Journal, 39(10), e321-e324. https://doi.org/10.1097/INF.0000000000002834

Farias, E. C. F. de, Justino, M. C. A., \& Mello, M. L. F. M. F. de. (2020). Síndrome inflamatória multissistêmica em criança associada à doença do coronavírus 19 na amazônia brasileira: Evolução fatal em lactente. Revista Paulista de Pediatria, 38.

Fornell, D. (2020). Kawasaki-like inflammatory disease affects children with COVID-19. Diagnostic and Interventional Cardiology.

Godfred-Cato, S., Bryant, B., Leung, J., Oster, M. E., Conklin, L., Abrams, J., Roguski, K., Wallace, B., Prezzato, E., Koumans, E. H., \& others. (2020). COVID-19-associated multisystem inflammatory syndrome in children-United States, March-July 2020. Morbidity and Mortality Weekly Report, 69(32), 1074

Greene, A. G., Saleh, M., Roseman, E., \& Sinert, R. (2020). Toxic shock-like syndrome and COVID-19: Multisystem inflammatory syndrome in children (MIS-C). The American Journal of Emergency Medicine, 38(11), 2492.e5-2492.e6. https://doi.org/10.1016/j.ajem.2020.05.117

Grimaud, M., Starck, J., Levy, M., Marais, C., Chareyre, J., Khraiche, D., Leruez-Ville, M., Quartier, P., Léger, P. L., Geslain, G., \& others. (2020). Acute myocarditis and multisystem inflammatory emerging disease following SARS-CoV-2 infection in critically ill children. Annals of Intensive Care, 10(1), 1-5.

Heidemann, S. M., Tilford, B., Bauerfeld, C., Martin, A., Garcia, R. U., Yagiela, L., \& Sarnaik, A. P. (2020). Three cases of pediatric multisystem inflammatory syndrome associated with COVID-19 due to SARS-CoV-2. The American Journal of Case Reports, 21, e925779-1.

Hopkins, J. (2020). Coronavirus Resource Center. https://coronavirus.jhu.edu/

Iannelli, A., Favre, G., Frey, S., Esnault, V., Gugenheim, J., Bouam, S., Schiavo, L., Tran, A., \& Alifano, M. (2020). Obesity and COVID-19: ACE 2, the Missing Tile. Obesity Surgery, 30(11), 4615-4617. https://doi.org/10.1007/s11695-020-04734-7

Jiang, L., Tang, K., Levin, M., Irfan, O., Morris, S. K., Wilson, K., Klein, J. D., \& Bhutta, Z. A. (2020). COVID-19 and multisystem inflammatory syndrome in children and adolescents. The Lancet Infectious Diseases, 20(11), e276-e288. https://doi.org/10.1016/S1473-3099(20)30651-4

Jiehao, C., Jin, X., Daojiong, L., Zhi, Y., Lei, X., Zhenghai, Q., Yuehua, Z., Hua, Z., Ran, J., Pengcheng, L., Xiangshi, W., Yanling, G., Aimei, X., He, T., Hailing, C., Chuning, W., Jingjing, L., Jianshe, W., \& Mei, Z. (2020). A Case Series of Children With 2019 Novel Coronavirus Infection: Clinical and Epidemiological Features. Clinical Infectious Diseases, 71(6), 1547-1551. https://doi.org/10.1093/cid/ciaa198

Jones, V. G., Mills, M., Suarez, D., Hogan, C. A., Yeh, D., Segal, J. B., Nguyen, E. L., Barsh, G. R., Maskatia, S., \& Mathew, R. (2020). COVID-19 and Kawasaki Disease: Novel Virus and Novel Case. Hospital Pediatrics, 10(6), 537-540. https://doi.org/10.1542/hpeds.2020-0123

Joseph, T. (2020). International Pneumologist's Consensus on COVID-19. 2.

Kaushik, S., Aydin, S. I., Derespina, K. R., Bansal, P. B., Kowalsky, S., Trachtman, R., Gillen, J. K., Perez, M. M., Soshnick, S. H., Conway, E. E., Bercow, A., Seiden, H. S., Pass, R. H., Ushay, H. M., Ofori-Amanfo, G., \& Medar, S. S. (2020). Multisystem Inflammatory Syndrome in Children Associated with Severe Acute Respiratory Syndrome Coronavirus 2 Infection (MIS-C): A Multi-institutional Study from New York City. The Journal of Pediatrics, 224, 2429. https://doi.org/10.1016/j.jpeds.2020.06.045

Kest, H., Kaushik, A., DeBruin, W., Colletti, M., \& Goldberg, D. (2020). Multisystem inflammatory syndrome in children (MIS-C) associated with 2019 novel coronavirus (SARS-CoV-2) infection. Case Reports in Pediatrics, 2020.

Kim, G. B. (2019). Reality of Kawasaki disease epidemiology. Korean journal of pediatrics, 62(8), 292.

Klocperk, A., Parackova, Z., Dissou, J., Malcova, H., Pavlicek, P., Vymazal, T., Dolezalova, P., \& Sediva, A. (2020). Case Report: Systemic Inflammatory Response and Fast Recovery in a Pediatric Patient With COVID-19. Frontiers in Immunology, 11, 1665. https://doi.org/10.3389/fimmu.2020.01665

Li, Q., Guan, X., Wu, P., Wang, X., Zhou, L., Tong, Y., Ren, R., Leung, K. S., Lau, E. H., Wong, J. Y., \& others. (2020). Early transmission dynamics in Wuhan, China, of novel coronavirus-infected pneumonia. New England Journal of Medicine, 382(13), 1199-1207. https://doi.org/10.1056/NEJMoa2001316

Licciardi, F., Pruccoli, G., Denina, M., Parodi, E., Taglietto, M., Rosati, S., \& Montin, D. (2020). SARS-CoV-2-Induced Kawasaki-Like Hyperinflammatory Syndrome: A Novel COVID Phenotype in Children. Pediatrics, 146(2), e20201711. https://doi.org/10.1542/peds.2020-1711 
Lu, X., Zhang, L., Du, H., Zhang, J., Li, Y. Y., Qu, J., Zhang, W., Wang, Y., Bao, S., Li, Y., Wu, C., Liu, H., Liu, D., Shao, J., Peng, X., Yang, Y., Liu, Z., Xiang, Y., Zhang, F., ... Wong, G. W. K. (2020). SARS-CoV-2 Infection in Children. New England Journal of Medicine, 382(17), 1663-1665. https://doi.org/10.1056/NEJMc2005073

Ludvigsson, J. F. (2020). Systematic review of COVID-19 in children shows milder cases and a better prognosis than adults. Acta Paediatrica, 109(6), 10881095. https://doi.org/10.1111/apa.15270

Mahajan, N., Chang, H. T., Leeman, R., Manalo, R., \& Glaberson, W. R. (2020). Case of multisystem inflammatory syndrome in children presenting as fever and abdominal pain. BMJ Case Reports, 13(9), e237306. https://doi.org/10.1136/bcr-2020-237306

Mamishi, S., Movahedi, Z., Mohammadi, M., Ziaee, V., Khodabandeh, M., Abdolsalehi, M. R., Navaeian, A., Heydari, H., Mahmoudi, S., \& Pourakbari, B. (2020). Multisystem inflammatory syndrome associated with SARS-CoV-2 infection in 45 children: A first report from Iran. Epidemiology and Infection, 148, e196. https://doi.org/10.1017/S095026882000196X

Masih, M., Moll, S., \& Raza, N. (2020). Paediatric case of prolonged COVID-19 manifesting as PMIS-TS and atypical Kawasaki. BMJ Case Reports, 13(9), e237194. https://doi.org/10.1136/bcr-2020-237194

Moazzam, Z., Salim, A., Hilal, K., \& Arshad, M. (2020). COVID-19 Multisystem Inflammatory Syndrome in Children (MIS-C) simulating as acute appendicitis: A case report. Journal of Pediatric and Adolescent Surgery, 1(1). https://doi.org/10.46831/jpas.v1i1.31

Moraleda, C., Serna-Pascual, M., Soriano-Arandes, A., Simó, S., Epalza, C., Santos, M., Grasa, C., Rodríguez, M., Soto, B., Gallego, N., Ruiz, Y., Urretavizcaya-Martínez, M., Pareja, M., Sanz-Santaeufemia, F. J., Fumadó, V., Lanaspa, M., Jordan, I., Prieto, L., Belda, S., ... EPICO-AEP Working Group. (2020). Multi-inflammatory Syndrome in Children Related to Severe Acute Respiratory Syndrome Coronavirus 2 (SARS-CoV-2) in Spain. Clinical Infectious Diseases, ciaa1042. https://doi.org/10.1093/cid/ciaa1042

Mozzini, C., \& Girelli, D. (2020). The role of Neutrophil Extracellular Traps in Covid-19: Only an hypothesis or a potential new field of research? Thrombosis Research, 191, 26-27. https://doi.org/10.1016/j.thromres.2020.04.031

Newburger, J. W., Takahashi, M., Gerber, M. A., Gewitz, M. H., Tani, L. Y., Burns, J. C., Shulman, S. T., Bolger, A. F., Ferrieri, P., Baltimore, R. S., Wilson, W. R., Baddour, L. M., Levison, M. E., Pallasch, T. J., Falace, D. A., \& Taubert, K. A. (2004). Diagnosis, Treatment, and Long-Term Management of Kawasaki Disease: A Statement for Health Professionals From the Committee on Rheumatic Fever, Endocarditis and Kawasaki Disease, Council on Cardiovascular Disease in the Young, American Heart Association. Circulation, 110(17), 2747-2771. https://doi.org/10.1161/01.CIR.0000145143.19711.78

Ng, K. F., Kothari, T., Bandi, S., Bird, P. W., Goyal, K., Zoha, M., Rai, V., \& Tang, J. W. (2020). COVID-19 multisystem inflammatory syndrome in three teenagers with confirmed SARS-CoV-2 infection. Journal of Medical Virology, 92(11), 2880-2886. https://doi.org/10.1002/jmv.26206

Nguyen, D. C., Haydar, H., Pace, E. R., Zhang, X. S., \& Dobbs, K. R. (2020). Pediatric Case of Severe COVID-19 With Shock and Multisystem Inflammation. Cureus. https://doi.org/10.7759/cureus.8915

Ong, J. S. M., Tosoni, A., Kim, Y., Kissoon, N., \& Murthy, S. (2020). Coronavirus Disease 2019 in Critically Ill Children: A Narrative Review of the Literature*. Pediatric Critical Care Medicine, 21(7), 662-666. https://doi.org/10.1097/PCC.0000000000002376

Pereira, A. S., Shitsuka, D. M., Parreira, F. J., \& Shitsuka, R. (2018). Metodologia da pesquisa científica. UFSM. https://repositorio.ufsm.br/bitstream/handle/1/15824/Lic_Computacao_Metodologia-Pesquisa-Cientifica.pdf?sequence=1

Pereira, M. F. B., Litvinov, N., Farhat, S. C. L., Eisencraft, A. P., Gibelli, M. A. B. C., Carvalho, W. B. de, Fernandes, V. R., Fink, T. de T., Framil, J. V. de S., Galleti, K. V., \& others. (2020). Severe clinical spectrum with high mortality in pediatric patients with COVID-19 and multisystem inflammatory syndrome. Clinics, 75.

Pouletty, M., Borocco, C., Ouldali, N., Caseris, M., Basmaci, R., Lachaume, N., Bensaid, P., Pichard, S., Kouider, H., Morelle, G., Craiu, I., Pondarre, C., Deho, A., Maroni, A., Oualha, M., Amoura, Z., Haroche, J., Chommeloux, J., Bajolle, F., \& Melki, I. (2020). Paediatric multisystem inflammatory syndrome temporally associated with SARS-CoV-2 mimicking Kawasaki disease (Kawa-COVID-19): A multicentre cohort. Annals of the Rheumatic Diseases, 79(8), 999-1006. https://doi.org/10.1136/annrheumdis-2020-217960

Raut, S., Roychowdhoury, S., Bhakta, S., Sarkar, M., \& Nandi, M. (2020). Incomplete Kawasaki Disease as Presentation of COVID-19 Infection in an Infant: A Case Report. Journal of Tropical Pediatrics, fmaa047. https://doi.org/10.1093/tropej/fmaa047

Regev, T., Antebi, M., Eytan, D., Shachor-Meyouhas, Y., Ilivitzki, A., Aviel, Y. B., \& Ben-Ari, J. (2020). Pediatric Inflammatory Multisystem Syndrome With Central Nervous System Involvement and Hypocomplementemia Following SARS-COV-2 Infection. Pediatric Infectious Disease Journal, 39(8), e206e207. https://doi.org/10.1097/INF.0000000000002804

Riphagen, S., Gomez, X., Gonzalez-Martinez, C., Wilkinson, N., \& Theocharis, P. (2020). Hyperinflammatory shock in children during COVID-19 pandemic. The Lancet, 395(10237), 1607-1608. https://doi.org/10.1016/S0140-6736(20)31094-1

Sampaio, C. A., Amorim, E. R. S., Sampaio, G. B. A., Bohrer, W. F. V. A., Vasconcelos, C. G., \& Oliveira, I. F. Relato de caso: síndrome inflamatória multissistêmica associada à infecção pelo SARS-CoV-2 em pediatria. Resid Pediatr, 202(0), 0.

Spencer, R., Closson, R. C., Gorelik, M., Boneparth, A. D., Hough, R. F., Acker, K. P., \& Krishnan, U. (2020). COVID-19 Inflammatory Syndrome With Clinical Features Resembling Kawasaki Disease. Pediatrics, 146(3), e20201845. https://doi.org/10.1542/peds.2020-1845

Stokes, E. K., Zambrano, L. D., Anderson, K. N., Marder, E. P., Raz, K. M., Felix, S. E. B., Tie, Y., \& Fullerton, K. E. (2020). Coronavirus disease 2019 case surveillance-United States, January 22-May 30, 2020. Morbidity and Mortality Weekly Report, 69(24), 759.

Toubiana, J., Poirault, C., Corsia, A., Bajolle, F., Fourgeaud, J., Angoulvant, F., Debray, A., Basmaci, R., Salvador, E., Biscardi, S., \& others. (2020). Kawasaki-like multisystem inflammatory syndrome in children during the covid-19 pandemic in Paris, France: Prospective observational study. bmj, 369. 
Research, Society and Development, v. 10, n. 3, e28710313242, 2021

(CC BY 4.0) | ISSN 2525-3409 | DOI: http://dx.doi.org/10.33448/rsd-v10i3.13242

Vari, D., Miller, J. M., Rellosa, N., Srivastava, S., Frizzola, M., \& Thacker, D. (2020). Severe cardiac dysfunction in a patient with multisystem inflammatory syndrome in children associated with COVID-19: Retrospective diagnosis of a puzzling presentation. A case report. Progress in Pediatric Cardiology, 58, 101270. https://doi.org/10.1016/j.ppedcard.2020.101270

Verdoni, L., Mazza, A., Gervasoni, A., Martelli, L., Ruggeri, M., Ciuffreda, M., Bonanomi, E., \& D’Antiga, L. (2020). An outbreak of severe Kawasaki-like disease at the Italian epicentre of the SARS-CoV-2 epidemic: An observational cohort study. The Lancet, 395(10239), 1771-1778. https://doi.org/10.1016/S0140-6736(20)31103-X

Waltuch, T., Gill, P., Zinns, L. E., Whitney, R., Tokarski, J., Tsung, J. W., \& Sanders, J. E. (2020). Features of COVID-19 post-infectious cytokine release syndrome in children presenting to the emergency department. The American Journal of Emergency Medicine, 38(10), 2246.e3-2246.e6. https://doi.org/10.1016/j.ajem.2020.05.058

Wang, G., Zhang, Y., Zhao, J., Zhang, J., \& Jiang, F. (2020). Mitigate the effects of home confinement on children during the COVID-19 outbreak. The Lancet, 395(10228), 945-947. https://doi.org/10.1016/S0140-6736(20)30547-X

Wang, J., Qi, H., Bao, L., Li, F., \& Shi, Y. (2020). A contingency plan for the management of the 2019 novel coronavirus outbreak in neonatal intensive care units. The Lancet Child \& Adolescent Health, 4(4), 258-259. https://doi.org/10.1016/S2352-4642(20)30040-7

Wang, W., Tang, J., \& Wei, F. (2020). Updated understanding of the outbreak of 2019 novel coronavirus (2019-nCoV) in Wuhan, China. Journal of Medical Virology, 92(4), 441-447. https://doi.org/10.1002/jmv.25689

Whittaker, E., Bamford, A., Kenny, J., Kaforou, M., Jones, C. E., Shah, P., Ramnarayan, P., Fraisse, A., Miller, O., Davies, P., Kucera, F., Brierley, J., McDougall, M., Carter, M., Tremoulet, A., Shimizu, C., Herberg, J., Burns, J. C., Lyall, H., \& for the PIMS-TS Study Group and EUCLIDS and PERFORM Consortia. (2020). Clinical Characteristics of 58 Children With a Pediatric Inflammatory Multisystem Syndrome Temporally Associated With SARS-CoV-2. JAMA, 324(3), 259. https://doi.org/10.1001/jama.2020.10369

WHO. (2020) Multisystem inflammatory syndrome in children and adolescents temporally related to COVID-19. de https://www.who.int/newsroom/commentaries/detail/multisystem-inflammatory-syndrome-in-children-andadolescents-with-covid-19

Wu, Z., \& McGoogan, J. M. (2020). Characteristics of and Important Lessons From the Coronavirus Disease 2019 (COVID-19) Outbreak in China: Summary of a Report of 72314 Cases From the Chinese Center for Disease Control and Prevention. JAMA, 323(13), 1239. https://doi.org/10.1001/jama.2020.2648) 